\title{
Who will go the extra mile? Selecting organizational citizens with a personality-based structured job interview
}

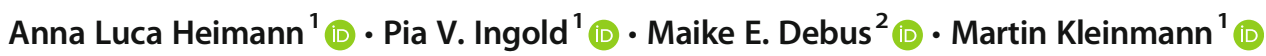

Accepted: 16 September 2020 / Published online: 7 October 2020

(C) The Author(s) 2020

\begin{abstract}
Employees' organizational citizenship behaviors (OCB) are important drivers of organizational effectiveness. Yet, there exist no established tools for selecting employees with a propensity to engage in OCB. Given that personality traits describe typical behavioral tendencies and are established OCB predictors, we propose that personality assessment is a useful approach for selecting employees who are likely to exhibit OCB. To test this proposition, we developed a structured job interview measuring the Big Five traits and then compared this interview to a personality self-report measure to determine which method of personality assessment works best for selecting organizational citizens. Employees $(N=223)$ from various occupations participated in the structured job interview and completed the personality self-report in a simulated selection setting. We then obtained supervisor ratings of employees' OCB. Results supported the assumption that structured job interviews can be specifically designed to assess the Big Five personality traits and, most importantly, to predict OCB. Interview ratings of specific personality traits differentially predicted different types of OCB (i.e., OCB-compliance, OCB-helping, and OCB-initiative) and explained incremental variance in OCB over and above personality self-reports and verbal cognitive ability. Taken together, these findings expand our knowledge about dispositional predictors of OCBs, personality assessment in selection, and the design of job interviews.
\end{abstract}

Keywords Organizational citizenship behavior $\cdot$ Personnel selection $\cdot$ Structured interviews $\cdot$ Personality traits

Organizations can benefit greatly from employees who engage in organizational citizenship behaviors (OCB; Koys, 2001; Podsakoff, Whiting, Podsakoff \& Blume, 2009). By definition, OCB refers to behaviors that contribute to the social and psychological context at work-such as upholding the rules, helping others, and taking initiative in advancing the organization (Organ, 1997; Organ, Podsakoff \& MacKenzie, 2006). Underlining its importance in the organizational context, OCB has been termed the "social lubricant" that keeps an organization running (Smith, Organ \& Near, $1983)$ or the "catalyst" that sparks task performance (Borman \& Motowidlo, 1997). As such, OCB has generated an enormous research interest: A simple PsycINFO search

Anna Luca Heimann

a.heimann@psychologie.uzh.ch

1 Department of Psychology, University of Zurich, Binzmuehlestrasse 14/Box 12, 8050 Zurich, Switzerland

2 School of Business, Economics, and Society, Friedrich-Alexander University Erlangen-Nürnberg, Erlangen, Germany shows that there were over 3000 publications revolving around OCB and related constructs. Given OCB's relevance, researchers concluded that "it would appear worthwhile for organizations to select employees who demonstrate a predisposition to exhibit OCB at work" (Organ, Podsakoff \& Podsakoff, 2011, p. 294). Yet, despite repeated calls to explicitly consider OCB as a criterion in personnel selection, research on how to predict OCB in selection settings has been surprisingly scarce (Borman \& Motowidlo, 1997; Organ et al., 2011; Werner, 2000).

In the present study, we aim to answer the aforementioned call by exploring a new approach for selecting organizational citizens: a personality-based structured job interview. We predict (a) that structured job interview questions will be useful tools for assessing manifestations of the Big Five personality traits, (b) that employees who are high in specific personality traits (i.e., Conscientiousness, Agreeableness, and Intellect/ Openness) will be likely to engage in specific OCBs (i.e., OCB-compliance, OCB-helping, and OCB-initiative), (c) that personality-based interview ratings will explain variance in OCBs above and beyond other measures such as a personality 
self-report and a test of verbal cognitive ability, and (d) that personality-based interview ratings will assess specific manifestations of personality and therefore will mediate the relationship between underlying personality traits and OCBs.

We focus on the assessment of personality traits because they tend to be considered major predictors of motivational (i.e., "will-do") performance criteria like OCB (Cortina and Luchman, 2013; Motowidlo, Borman \& Schmit, 1997). As compared to other OCB predictors (i.e., job attitudes; Hoffman, Blair, Meriac \& Woehr, 2007), personality traits may be relatively stable within a given domain (e.g., in the context of work; Judge, Simon, Hurst \& Kelley, 2014; Woods \& Hampson, 2010). Hence, employees are likely to "bring" their personality with them when they start a new job (see also Sackett, Lievens, Van Iddekinge \& Kuncel, 2017), and this can make it viable to assess personality in order to identify those employees who possess a predisposition to engage in OCB.

Moreover, the structured job interview seems a feasible method for assessing personality traits in the context of selection (Levashina, Hartwell, Morgeson and Campion, 2014). One reason may be that structured interviews are part of many selection procedures (e.g., Jackson, Dewberry, Gallagher \& Close, 2018; König, Klehe, Berchtold \& Kleinmann, 2010). They are standardized (e.g., all interviewees answer the same questions; Campion, Palmer \& Campion, 1997), they are perceived more favorably by applicants than traditional personality measures (i.e., self-report questionnaires; Anderson, Salgado \& Hülsheger, 2010), and they have consistently shown to predict job performance (Huffcutt, Culbertson \& Weyhrauch, 2014; McDaniel, Whetzel, Schmidt \& Maurer, 1994). In this regard, it is important to note that the content of structured interviews needs to be job-related in order for the interview to predict job performance (Campion et al., 1997; McDaniel et al., 1994). Following this rationale, interview questions should refer to the context of work if they aim to assess personality traits to predict OCB. This is in line with Levashina et al. (2014) who post that in order to assess personality with structured interviews, interview questions should be "designed to measure the specific job-related behaviors that are presumed to underlie a particular personality trait" (p. 265).

By combining research on OCB, personality assessment, and job interviews, this study contributes to the literature in several ways. First, we provide a novel examination as to whether certain personality traits within the realm of the Big Five (Goldberg, 1990; Hofstee, de Raad \& Goldberg, 1992) differentially predict different types of OCBs. Hence, this study aims at expanding our knowledge about which personality traits are most relevant for predicting specific citizenship behaviors. Second, this study is among the first to examine relationships between all Big Five traits and different types of $\mathrm{OCB}$ in the context of personnel selection (see for example
Wang \& Bowling, 2016). Even though the selection context affects how participants report their personality (Birkeland, Manson, Kisamore, Brannick \& Smith, 2006; Schmit \& Ryan, 1993), previous research on personality and OCB has normally been conducted in settings that do not reflect or simulate selection situations (e.g., Kluemper, DeGroot \& Choi, 2013; Wang \& Bowling, 2016). Third, this study introduces a job interview designed to assess manifestations of the Big Five traits and, thus, informs the debate on which methods (other than traditional self-report measures) can be used to assess personality in the context of selection (e.g., Morgeson et al., 2007; Ones, Dilchert, Viswesvaran \& Judge, 2007; Rothstein \& Goffin, 2006; Salgado, 2016). Fourth, we aim to deepen our conceptual understanding as to why interview ratings are adequate OCB predictors. For this purpose, we test the assumption that interview ratings capture specific expressions of personality traits which link underlying personality traits to citizenship behaviors.

\section{OCB as a criterion in personnel selection}

Previous research has placed attention on OCB as a potential criterion in personnel selection (Borman \& Motowidlo, 1993; Organ et al., 2011; Werner, 2000) because OCB is typically regarded as an integral part of the larger job performance domain (Hoffman et al., 2007; Koopmans et al., 2011; Viswesvaran \& Ones, 2000). In line with this, supervisors and decision-makers tend to take OCB into account when evaluating employees' job performance (Podsakoff et al., 2009; Podsakoff, Whiting, Podsakoff \& Mishra, 2011), and research has illustrated that OCBs are related to a number of important organizational outcomes such as higher productivity and lower turnover rates (Koys, 2001; Podsakoff et al., 2009).

Research has further identified different types of citizenship behaviors that are directed at benefiting the context of work in different ways (e.g., Organ et al., 2006). In line with previous research on OCB in the context of selection (Allen, Facteau \& Facteau, 2004; Podsakoff et al., 2011), the present study focuses on three forms of OCB: compliance, helping, and initiative. OCB-compliance and OCB-helping have received considerable attention because they constitute the first OCB dimensions identified in the literature (Organ et al., 2006; Smith et al., 1983). OCB-compliance can be characterized by following the rules of the organization and by showing low levels of absenteeism (Smith et al., 1983). Hence, OCBcompliance is often understood as a form of OCB directed at the organization (i.e., OCB-O; Williams and Anderson, 1991). OCB-helping includes prosocial behaviors such as preventing conflicts among co-workers, helping other co-workers with their tasks when needed, and cheering co-workers up (Organ et al., 2006). Thus, OCB-helping is a form of OCB directed at 
other individuals (i.e., OCB-I; Williams \& Anderson, 1991). More recently, change-oriented forms of OCB, such as OCBinitiative, have received considerable attention in research on job performance (Chiaburu, Oh, Berry, Li \& Gardner, 2011; Marinova, Peng, Lorinkova, Van Dyne \& Chiaburu, 2015). OCB-initiative refers to employees' active and constructive involvement in the governance of the organization and has also been labeled as civic virtue (Graham, 1986; Konovsky \& Organ, 1996; Organ, 1988; Organ et al., 2006). It can encompass behaviors such as keeping oneself informed about what is going on in the organization and making innovative suggestions for change.

\section{Personality traits as predictor constructs}

Conceptually, personality traits, such as the Big Five (Extraversion, Emotional Stability, Conscientiousness, Agreeableness, and Intellect/Openness) describe how individuals typically think, feel, and behave (Goldberg, 1990, 1992). According to theories of job performance, personality traits determine the knowledge, skills, and habits individuals acquire, and thereby shape how individuals behave at work (Bergman, Donovan, Drasgow, Overton \& Henning, 2008; Dudley \& Cortina, 2008; Motowidlo et al., 1997). In support of this, meta-analyses provide some evidence that the Big Five traits relate to different citizenship behaviors (Borman, Penner, Allen \& Motowidlo, 2001; Chiaburu et al., 2011; Dalal, 2005; Hurtz \& Donovan, 2000; Ilies, Fulmer, Spitzmuller \& Johnson, 2009; LePine, Erez \& Johnson, 2002; Marinova et al., 2015; Organ and Ryan, 1995).

Although there is a consistent pattern of findings that encourages the use of personality traits for predicting OCB, it is important to note two limitations: First, extant research on dispositional OCB predictors has relied to a large degree on traditional self-report measures for assessing personality (e.g., Organ et al., 2011). This might be problematic because personality self-report measures - in selection contexts - have been criticized for being more vulnerable to intentional response distortion than other selection instruments (e.g., structured interviews; Van Iddekinge, Raymark \& Roth, 2005). Second, and relatedly, there are very few studies that have examined the relationships between personality traits and OCB within an actual or simulated selection context. Two studies using data from actual selection settings (Anglim, Lievens, Everton, Grant \& Marty, 2018; Hogan, Rybicki, Motowidlo \& Borman, 1998) and one study with data from a simulated selection setting (Blickle, Momm, Schneider, Gansen \& Kramer, 2009) found that different personality traits predict OCB. Yet, these studies (a) employed self-reports only for assessing personality traits, (b) did not all differentiate between several types of OCB, and (c) found somewhat inconsistent patterns of results (i.e.,
Conscientiousness being predictive of OCB in Blickle et al., 2009; versus Adjustment, Prudence, and Ambition being predictive of OCB in Hogan et al., 1998; versus Agreeableness and Extraversion being predictive of OCB in Anglim et al., 2018). Specifically, in the selection context, exploring methods other than self-reports might offer a promising opportunity to improve personality assessment and thereby the pinpoint prediction of different OCBs.

\section{Structured interviews as predictor methods}

Structured interviews are widely established selection methods with features that may improve the assessment of personality predictors in personnel selection (Levashina et al., 2014). Specifically, personality measures have shown to be better at predicting work-related performance criteria when they are contextualized (i.e., designed to match the context of work) and, thereby, provide a clear frame-of-reference for applicants (Shaffer \& Postlethwaite, 2012; Wang \& Bowling, 2016). Job interviews may be regarded as contextualized measures because the content of interview questions is likely to be associated with the context at work (e.g., Levashina et al., 2014). In addition, interviews feature an open response format (see Raymark \& Van Iddekinge, 2013). This open response format places high cognitive demands on applicants and has been found to decrease intentional response distortions in comparison to self-report responses on personality measures (Van Iddekinge et al., 2005).

Going beyond the assessment of personality traits, the structured interview has already been proposed as a potential method to predict OCB (Organ et al., 2011; Werner, 2000). Two studies have examined structured job interviews as predictors of OCB so far, but none of them has used a personality-based interview. Latham and Skarlicki (1995) and Allen et al. (2004) both developed interview questions for assessing $\mathrm{OCB}$ and found that their interview ratings partly predicted co-worker ratings of OCB. Despite these first promising findings, some fundamental questions remain to be answered because previous studies have yielded inconsistent results. The former study (Latham \& Skarlicki, 1995) found that only some of the developed interview questions predicted OCB (i.e., behavior description interview questions did not predict OCB), and the latter study (Allen et al., 2004) reported that interview ratings were only predictive of some of the examined citizenship behaviors (e.g., their interview ratings did not predict OCB directed at other individuals). In addition, both studies did not examine the prediction of supervisor ratings of $\mathrm{OCB}$, but peer-ratings of $\mathrm{OCB}$. In contrast to this approach, employees' performance in the selection context is most frequently assessed via supervisor ratings (Woehr and Roch, 2012), and supervisor ratings have shown to be the best single predictors of independent performance criteria 
when compared to self- and peer-ratings (Atkins \& Wood, 2002; Darr \& Catano, 2008).

\section{A personality-based structured job interview for predicting OCB}

Addressing the limitations of previous research on personality traits and structured interviews as predictors of OCB, the present study has four consecutive purposes: We aim to establish (a) construct-related validity evidence for a structured job interview assessing the Big Five, (b) criterion-related validity evidence for this interview by carefully linking the Big Five traits to supervisor ratings of specific OCBs, (c) incremental validity evidence of personality-based interview ratings over and above personality self-reports and verbal cognitive ability in predicting $\mathrm{OCB}$, and $(\mathrm{d})$ evidence that interview ratings are more proximal to OCB as compared to traditional personality self-reports because interview questions capture specific manifestations of personality.

First, gathering construct-related validity evidence may be a central prerequisite for testing whether a personality-based job interview is a useful approach for selecting organizational citizens (see also Hamdani, Valcea \& Buckley, 2014). This is likely to be relevant given that research on assessing personality traits with job interview questions has been scarce: Although interview questions often assess personalityrelated interview dimensions among many others (e.g., drive, decisiveness, sense of duty, and likability; Huffcutt, Conway, et al., 2001a), these interview dimensions are oftentimes not aligned with established personality frameworks such as the Big Five. In line with this, previous studies examining personality saturation in structured interviews found low correspondence between traditional job interviews and personality self-reports with uncorrected meta-analytic estimates ranging from .01 to .17 (Roth, Van Iddekinge, Huffcutt, Eidson Jr. \& Schmit, 2005; Salgado \& Moscoso, 2002).

In their review, Levashina et al. (2014) summarized 18 research articles on personality and structured interviews. They identified one study that explicitly developed structured interview questions for assessing personality traits (Van Iddekinge et al., 2005). Although this study only focused on specific facets of three selected traits (i.e., Vulnerability, Altruism, and Self-Discipline) and did not collect criterion data, the findings support the proposition that structured interview questions have the potential to measure established personality constructs (Van Iddekinge et al., 2005). In line with these findings, Levashina et al. (2014) conclude that "research should further examine personality-based structured interviews as an alternative method of applicant personality selfassessment" (p. 264).

When assessing the Big Five personality traits with a structured job interview, we argue that a patterned behavior description interview (see Janz, 1982) is a particularly useful interview format: Behavior description interview questions are thought to primarily capture interviewees' job experience and personality (Levashina et al., 2014). In this interview type, applicants report their own past behavior in previously encountered situations (Janz, 1982). Given that personality traits are considered to manifest in behaviors (e.g., Tett \& Burnett, 2003), evaluating interviewees' past behaviors in actually experienced situations would allow for insight into interviewees' personality. Accordingly, we hypothesize that the Big Five personality traits can be measured as dimensions in a behavior description interview. To test this assumption, we posit the following hypothesis:

Hypothesis 1: A factor model specifying the Big Five personality traits as distinct and correlated latent factors will best represent the data structure of the developed interview.

Second, and regarding criterion-related validity, it is conceivable that the Big Five personality traits, being distinct constructs, differentially predict different forms of OCB. In line with this, we test the interviews' criterion-related validity by establishing differential hypotheses for the prediction of OCB-compliance, OCB-helping, and OCB-initiative, respectively. Thereby, we follow Borman and Motowidlo (1997) who highlight that "evidence toward establishing empirical links between personality constructs and relatively specific criterion constructs contributes importantly to the science of personnel selection" (p. 108).

Specifically, we propose that interview ratings of Conscientiousness are particularly predictive of OCB-compliance-for the following reasons: Individuals scoring high on Conscientiousness tend to feel responsible and act reliably; they are industrious and hard-working (Goldberg, 1990; Hofstee et al., 1992). As they are likely to feel a sense of duty towards their work, conscientious employees may be more likely to engage in behaviors that maintain a productive work environment such as OCB-compliance (see also Chiaburu et al., 2011; Ilies et al., 2009). We conclude that Conscientiousness will be the strongest personality predictor of OCB-compliance, thus arriving at the following prediction:

Hypothesis 2: Conscientiousness assessed in the structured job interview will predict OCB-compliance as rated by supervisors over and above the other Big Five traits.

Furthermore, we hypothesize that interview ratings of Agreeableness are particularly predictive of OCB-helping. Individuals scoring high on Agreeableness value social harmony and tend to be sympathetic, understanding, and cooperative (Goldberg, 1990; Hofstee et al., 1992). As they are striving to have positive relationships with others, agreeable 
employees may tend to engage in OCB-helping which benefits other individuals at work (see also Chiaburu et al., 2011; Ilies et al., 2009). We expect that Agreeableness is the most relevant predictor of OCB-helping and therefore posit:

Hypothesis 3: Agreeableness assessed in the structured job interview will predict OCB-helping as rated by supervisors over and above the other Big Five traits.

In addition, interview ratings of Intellect/Openness should be particularly predictive of OCB-initiative. This is because individuals scoring high on Intellect/Openness are imaginative, independent, creative, curious, and full of ideas (Goldberg, 1990; Hofstee et al., 1992). As they are open to trying new things and are likely to have new ideas, employees high on Intellect/Openness may often engage in OCB-initiative to enhance and advance their work environment (see also Chiaburu et al., 2011; Marinova et al., 2015). Accordingly, we hypothesize that Intellect/Openness is the strongest predictor of OCB-initiative, and thus, we predict:

Hypothesis 4: Intellect/Openness assessed in the structured job interview will predict OCB-initiative as rated by supervisors over and above the other Big Five traits.

A question of more practical relevance is whether the newly-developed personality-based interview shows incremental validity over and above other measures such as a personality self-report questionnaire and a verbal cognitive ability test. Personality questionnaires have the advantage that they are simple to administer, tend to be cost-efficient, and can be easily contextualized (i.e., adapted to reference to the work setting; Shaffer \& Postlethwaite, 2012; Wang $\&$ Bowling, 2016). Cognitive ability tests are also relatively simple to administer and part of many selection procedures (e.g., Wee, Newman \& Joseph, 2014). Previous research demonstrated that cognitive ability is a predictor of both job interview ratings (Berry, Sackett \& Landers, 2007; Roth \& Huffcutt, 2013) and OCB (Gonzalez-Mulé, Mount \& Oh, 2014). Hence, the criterion-related validity of interview ratings in predicting OCB could potentially be driven by interview ratings capturing cognitive ability. In particular, verbal cognitive ability (e.g., having a rich vocabulary, being able to express oneself) seems relevant to interview ratings, given that interviewee performance is thought to be influenced by the verbal content of interview responses and the verbal delivery of these responses (Huffcutt, Van Iddekinge \& Roth, 2011). Therefore, investigating whether the interview explains variance in $\mathrm{OCB}$ beyond both a personality self-report questionnaire and a verbal cognitive ability test is warranted to determine if the costs of developing and administering a personality-based interview are justified (Barrick, Patton \& Haugland, 2000; Macan, 2009; Van Iddekinge et al., 2005).
More specifically, a personality-based structured interview may be more predictive of OCB than a contextualized selfreport questionnaire as the interview seems to allow for a more comprehensive assessment of applicants' personality. This is because the interview method features an open response format and asks for applicants' cognitions, emotions, and behaviors in specific situations. In line with this, Raymark and Van Iddekinge (2013) pointed out that personality-based interviews are especially rich in information as they "require the applicant to generate detailed responses to job-related scenarios" (p. 428). These detailed responses provide the interviewers with comprehensive information on how the applicant perceives a number of job-related situations and how the applicant chooses to behave in these situations. Hence, we make the following predictions regarding the incremental validity of the personality-based interview:

Hypothesis 5a: Conscientiousness assessed in the structured job interview will explain variance in OCBcompliance as rated by supervisors over and above contextualized self-reports of Conscientiousness and verbal cognitive ability.

Hypothesis 5b: Agreeableness assessed in the structured job interview will explain variance in OCB-helping as rated by supervisors over and above contextualized selfreports of Agreeableness and verbal cognitive ability.

Hypothesis 5c: Intellect/Openness assessed in the structured job interview will explain variance in OCBinitiative as rated by supervisors over and above contextualized self-reports of Intellect/Openness and verbal cognitive ability.

Finally, it is vital to better understand how personality and OCB are linked to each other and why the interview method should be a useful approach for identifying organizational citizens. An explanation as to why interview ratings are predictive of OCB is that the interview method can capture situation-specific manifestations of personality that are most proximal to performance-relevant behavior in the workplace such as OCB. While personality self-reports are supposed to assess relatively stable dispositions (e.g., Hough \& Furnham, 2003; Sackett et al., 2017; Wrzus \& Mehl, 2015), interview ratings focus on how these dispositions reflect on employees' thoughts, feelings, and behaviors in given situations. These situation-specific manifestations of personality might be good indicators of whether (or to what extent) employees exhibit OCB because it is in these situations that employees decide to engage in behaviors such as following rules, helping others, or trying to change something within the organization. If these assumptions hold true, interview ratings of personality traits (i.e., cognitive, emotional, and behavioral manifestations of personality) should mediate the relationship between selfreported personality traits (i.e., general dispositions) and 
OCB (i.e., performance-relevant behaviors at the workplace). Accordingly, we posit:

Hypothesis 6a: Interview ratings of Conscientiousness will mediate the relationship between self-reported Conscientiousness and supervisor-rated OCBcompliance.

Hypothesis 6b: Interview ratings of Agreeableness will mediate the relationship between self-reported Agreeableness and supervisor-rated OCB-helping. Hypothesis 6c: Interview ratings of Intellect/Openness will mediate the relationship between self-reported Intellect/Openness and supervisor-rated OCB-initiative.

\section{Method}

\section{Sample}

\section{Interviewees}

Interviewees were 223 (91 women, 132 men) individuals who completed a job interview in a simulated selection setting at a European university. We recruited interviewees through the career services departments of vocational training institutions, several universities, social media, and advertisements in local newspapers. Interviewees participated in the simulated selection procedure to prepare themselves for future job applications. In return for their participation, they received comprehensive performance feedback and general advice on job applications. As a precondition, all interviewees had to be employed and were asked to provide the contact details (name and e-mail address) of their direct supervisor upon signing up for the study so that we could collect supervisor ratings of interviewees' OCB. Mean age of interviewees was 30.56 $(S D=7.32)$ years. Most interviewees $(82 \%)$ held an academic degree, and more than half of interviewees $(63 \%)$ had already participated in three or more formal job interviews. They had been working in their current job for $2.57(S D=2.22)$ years on average. Interviewees were asked to categorize their current jobs. In general, we found that interviewees held a great variety of different jobs. Almost one third of interviewees (30\%) indicated that they had a job as researchers and developers, $12 \%$ worked as administrative assistants, $10 \%$ worked as project managers, $8 \%$ as financial analysts or accountants, $6 \%$ worked as instructors or lecturers, $4 \%$ worked as IT professionals, $4 \%$ as sales persons, $3 \%$ as human resources managers, $3 \%$ as marketing professionals, $3 \%$ worked as supply chain managers, $2 \%$ had a job as technical staff, $2 \%$ worked as customer service representatives, $2 \%$ as public relations professionals, $2 \%$ as health service professionals, $1 \%$ as executive managers, $1 \%$ as quality assurance managers, $1 \%$ as media professionals, and $5 \%$ did not indicate any of these categories.

\section{Supervisors}

Supervisors received a link to an online questionnaire that included demographic questions and questions on interviewees' OCB. Supervisors' response rate was $90 \%$ (i.e., the questionnaire was returned for 200 out of the 223 interviewees). In total, 198 supervisors (56 women, 142 men) completed the questionnaire; of these, 196 supervisors rated one interviewee and two supervisors rated two interviewees. Supervisors' mean age was $44.27(S D=9.88)$ years. Most of them $(83 \%)$ had been working together with the rated interviewee for more than 1 year. They reported that they could evaluate interviewees' behavior on the job well on a scale from $1=$ badly to $5=$ well, with a mean score of $4.61(S D=$ 0.62 ) and a mode score of 5. We did not exclude any supervisor from the sample because none of them indicated that they were not able to evaluate interviewees. Supervisors did not receive any information about their employees' performance in the simulated selection procedure (i.e., supervisors did not have access to interview ratings or personality scores), and supervisor ratings were confidential (i.e., interviewees did not have access to their supervisor's rating).

\section{Interviewers}

Interviewers were 78 (61 women, 17 men) advanced psychology students who were on average $28.04(S D=7.91)$ years old and had studied psychology as a major for $6.68(S D=$ 2.28) semesters on average. Prior to participating in this study, interviewers had completed a 1-day frame-of-reference interviewer training (Roch, Woehr, Mishra \& Kieszczynska, 2012; Woehr \& Huffcutt, 1994). During this training, interviewers were informed about the position they were interviewing for (i.e., they received a job ad), learned about the interview dimensions (here: the Big Five personality traits), and were given the opportunity to practice administering and rating the interview questions in small groups. They were provided with an interview guide which had instructions on how to start and end the interview in a standardized manner and on how to behave during the interview (e.g., they could repeat each interview question once but probing was not allowed in the interview). Interviewers had no access to interviewees' selfreports and ratings from interviewees' supervisors, and they were blind to the hypotheses of this study.

\section{Procedure}

We used a simulated selection setting similar to those that have been successfully employed in previous studies (e.g., Barrick et al., 2000; Swider, Barrick \& Harris, 2016; Van 
Iddekinge et al., 2005; Van Iddekinge, Raymark, Roth \& Payne, 2006). We opted to use a simulation because we wanted to examine the interview's validity in a controlled setting where interviewers do not have previous knowledge about interviewees that may influence perceptions of personality (e.g., their résumé or results from previous tests) and where employed interviewees would allow us to collect OCB ratings from their supervisors. Interviewees were explicitly instructed to behave as if they were applying for a management trainee position. We chose this type of position because it is typically open to individuals from different professional and educational backgrounds. Before starting with the simulated selection procedure, interviewees were given a job ad for this position with a short description of the company, the position, and the skills needed for this position. The same job ad had previously been given to interviewers. The job ad was similar to those described in previous studies using a simulated selection setting (e.g., Ingold, Kleinmann, König \& Melchers, 2016).

Interviewees completed a personality-based job interview and a contextualized personality self-report within the simulated selection setting. Selection instruments were presented in randomized order so that half of the interviewees filled in the contextualized personality self-report first, whereas the other half completed the personalitybased interview first. The personality-based interview contained 15 interview questions (i.e., three questions per trait) and took $30 \mathrm{~min}$ in total. It was possible to conduct the interview within this time frame because the interview was highly structured to prevent non-formalized interactions between interviewers and interviewees. Specifically, interviewers were instructed to closely adhere to the interview guide not allowing for (a) paraphrasing or explaining interview questions, (b) reading out interview questions to interviewees more than once, or (c) asking any follow-up questions (i.e., probing). In addition, interviewees were instructed to keep their responses short.

A panel of two interviewers administered each interview. Interviewer pairs were not constant but changed across interviewees to minimize interviewer effects and to assure that interviewers were randomly assigned to interviewees. Interviewers took notes on interviewees' responses to each interview question and then individually rated the responses. At the end of the simulation, interviewers had time to compare and to discuss their individual ratings for each interview question if their ratings diverged. At the same time, interviewees responded to questions on the perceived authenticity of the simulated selection procedure. Afterwards, interviewees received extensive feedback on their interview performance in order to prepare them for future job applications.

\section{Measures}

\section{Personality-based job interview}

We developed a behavior description interview (based on Janz, 1982) to assess the Big Five personality traits. The interview assessed specific behaviors at work as indicators of the Big Five personality traits. Interview development proceeded in five steps. First, we collected specific behaviors that (a) were characteristic of the Big Five personality traits and (b) could be observed in the context of work. To collect these behaviors, we considered two established personality questionnaires: the 50-item questionnaire from the International Personality Item Pool (IPIP; Goldberg, 1992) and the NEO Five Factor Inventory (NEO-FFI; Costa \& McCrae, 1989; McCrae \& Costa, 2004).

Second, the first author of this study developed a pool of 60 interview items describing situations at work in which the previously collected personality-related behaviors can be observed. Co-authors of this study then carefully revised this pool of interview items several times by adapting them to meet the following criteria: (a) interview items had to refer to situations that every interviewee had already experienced at work regardless of their specific jobs, (b) interview items had to refer to situations that elicit behaviors which can be clearly assigned to one personality trait, (c) interview items had to refer to situations that allow for variability in the responses of interviewees, and (d) the structure of interview items (e.g., wordings, length of each item) needed to be similar for all interview items. This process led to a set of 20 interview items.

Third, 5-point rating scales with behavioral anchors for each of the 20 interview items were developed. The first author constructed behavioral anchors that were typical of low, average, and high characteristics of the respective personality trait based on items from personality questionnaires, namely the IPIP (Goldberg, 1992) and the NEO-FFI (McCrae \& Costa, 2004), and adapted the behavioral anchors to the context of the interview items. Co-authors of this study then independently reviewed the ratings scales and provided feedback on how to make them applicable for a majority of jobs.

Fourth, to ensure the content validity of interview questions, five subject matter experts (i.e., I-O psychologists specialized in personnel selection; none of whom were co-authors of the present study) provided evaluations on the developed behavior description interview questions consisting of 20 interview items and their respective rating scales. For every interview question, the experts rated how accurately the respective question tapped into each personality trait. In addition, experts indicated if they expected variability in the responses of different interviewees to the interview questions. Furthermore, the experts provided written feedback on the relevance and suitability of the behavioral anchors (i.e., evaluating questions such as "Are behavioral anchors likely to be 
observable in different kind of jobs?", "Do behavioral anchors fit with the respective interview item?"). Finally, on the basis of these evaluations, the authors of the present study (a) discarded interview questions that had been evaluated as less effective for assessing the intended personality trait and (b) revised interview items and behavioral anchors according to the feedback provided by subject matter experts.

The final personality interview consisted of 15 behavior description interview questions. Each interview question was designed to measure only one personality trait, and each personality trait was measured with three interview questions. An example interview question for each personality trait is presented in Appendices 1 to 5.

Two interviewers rated interviewees' responses to each interview question on a 5 -point scale ranging from $1=n o t$ characteristic to $5=$ highly characteristic regarding the respective personality trait. After having completed all interviews together, interviewers discussed their individual ratings if these ratings were discrepant by two points or more. Interviewers did not have to agree on the same final rating but were allowed to make final changes to their ratings. To determine interviewers' interrater reliability, we calculated a one-way random effects ICC for every interview question. Across the 15 interview questions, the ICC for the interviewer panel was .78 and the mean correlation between interviewers' ratings of each interview question was $\bar{r}=.65$. Thus, interrater reliability in this study was comparable to the personality-based interview from Van Iddekinge et al. (2005) with a mean ICC of .74 and a mean correlation between interviewers' ratings of $\bar{r}=.60$. We then averaged ratings across the two interviewers.

\section{Contextualized personality self-report}

Interviewees completed the 50-item sample questionnaire from the International Personality Item Pool (IPIP; Goldberg, 1992) which has previously been used by Lievens, De Corte \& Schollaert (2008) to obtain contextualized personality self-reports. Similar to previous studies, all items were adapted to the context of work by adding the tag "at work" (e.g., Bowling \& Burns, 2010; Wang \& Bowling, 2016). Interviewees indicated how accurate each item described themselves on a 5-point scale ranging from $1=$ very inaccurate to $5=$ very accurate. Each Big Five personality trait was measured with 10 items. Example items are "At work, I make friends easily" (Extraversion), "At work, I sympathize with others' feelings" (Agreeableness), "At work, I pay attention to details" (Conscientiousness), "At work, I get stressed out easily" (reverse-coded, Emotional Stability), and "At work, I am full of ideas" (Intellect/Openness). In this study, internal consistencies ranged from $\alpha=.75$ (Conscientiousness) to $\alpha=.85$ (Emotional Stability) and were similar to the internal consistencies reported by Lievens et al.
(2008) which ranged from $\alpha=.76$ (Intellect/Openness) to $\alpha=.89$ (Emotional Stability).

\section{Verbal cognitive ability}

To measure interviewees' verbal cognitive ability, we used the verbal reasoning module of the IST 2000 (Amthauer, Brocke, Liepmann \& Beauducel, 1999), a comprehensive and established cognitive ability test that has previously been used in different fields of psychological research (e.g., Freudenthaler \& Neubauer, 2005; Hülsheger, Maier \& Stumpp, 2007; Jansen, Lievens \& Kleinmann, 2011; Mortensen et al., 2014). The verbal reasoning module comprises three 20-item subtests including tasks such as completing sentences, understanding analogies, and finding similarities. In this study, the internal consistency for the verbal reasoning module was $\alpha=.81$, which was similar to the internal consistency reported by the test developers being $\alpha=.88$ (Amthauer et al., 1999). Previous research reported correlations of this verbal cognitive ability measure with career success to be $r=.35$ and with educational success to be $r=.43$ (Steinmayr \& Amelang, 2006).

\section{Supervisor ratings of $O C B$}

We measured OCB-compliance, OCB-helping, and OCBinitiative with three subscales from a validated $\mathrm{OCB}$ questionnaire from Staufenbiel and Hartz (2000), which is based on the OCB scales from Niehoff and Moorman (1993). All items were rated on a 7-point scale ranging from $1=$ not at all to $7=$ absolutely. OCB-compliance was measured with the 5item subscale labeled generalized compliance which has been used in several previous studies (e.g., Debus, Greulich, König \& Kleinmann, 2019; Strobel, Tumasjan, Spörrle \& Welpe, 2013; Zettler and Solga, 2013). An example items is "This employee follows rules and instructions with great accuracy". The internal consistency of the scale was $\alpha=.79$. OCBhelping was measured with the 5-item subscale labeled altruism (see also Binnewies, Sonnentag \& Mojza, 2009; Krumm, Grube \& Hertel, 2013; Lehmann-Willenbrock, Grohmann \& Kauffeld, 2013). An example item is "This employee helps co-workers if they are overloaded with work". The internal consistency of the scale was $\alpha=.84$. OCBinitiative was measured with the 5 -item subscale labeled individual initiative which has been used in previous studies (e.g., Lehmann-Willenbrock et al., 2013; Sackmann, EggenhoferRehart \& Friesl, 2009). An example item is "This employee makes innovative suggestions to improve the quality of our work". The internal consistency of the scale was $\alpha=.85$. Taken together, the internal consistencies of the three scales in the present study were similar to the internal consistencies reported by the authors of the scales, being $\alpha=.76, \alpha=.87$, and $\alpha=.87$, respectively (Staufenbiel \& Hartz, 2000). A 
principal factor analysis of all 15 items further supported a three-factor solution that accounted for $51 \%$ of the variance in the present sample (average loading on the designated factor was .62). The scale developers reported correlations of these three OCB scales with job satisfaction ranging from $r=.32$ to $r=.54$ and with task-based performance ranging from $r=.59$ to $r=.63$ (Staufenbiel \& Hartz, 2000).

\section{Further measures}

At the end of the simulation, we asked interviewees control questions to check for the perceived authenticity of the selection setting. Interviewees answered the following items on a 6point scale ranging from $1=$ strongly disagree to $5=$ strongly agree: "During the simulation, I behaved as if I would have behaved in an actual selection setting", "I perceived the selection simulation as realistic", and "It was easy to adapt to the role of an applicant".

\section{Results}

We first examined whether interviewees had perceived the simulated selection setting as authentic. Interviewees reported that they behaved as if they were in an actual selection process ( $M=3.93, S D=0.82$, with a mode score of 4 on a scale from $1=$ strongly disagree to $5=$ strongly agree $)$, that they perceived the selection simulation as realistic $(M=3.59, S D=$ 0.87 , with a mode score of 4 on a scale from $1=$ strongly disagree to $5=$ strongly agree), and that they could easily adapt to the role of an applicant $(M=3.57, S D=0.96$, with a mode score of 4 on a scale from $1=$ strongly disagree to $5=$ strongly agree). We did not exclude any interviewees from the sample because no interviewee strongly disagreed with all items. Table 1 presents means, standard deviations, and intercorrelations among all study variables.

\section{Assessing personality: Construct-related validity of interview ratings}

Hypothesis 1 posited that a factor model specifying the Big Five as dimension factors would best represent the internal structure of interview ratings. To test this hypothesis, we conducted a set of confirmatory factor analyses (CFAs) determining whether interview ratings reflected the Big Five personality traits. Therefore, we used the lavaan package (version 0.522) for the R environment (Rosseel, 2012). We applied full information maximum likelihood estimation with robust (i.e., Huber-White) standard errors and a robust chi-square test statistic (see also Maydeu-Olivares, 2017). Every latent Big Five personality trait was measured with three interview questions as indicators.
In support of Hypothesis 1, the hypothesized model specifying the Big Five as distinct but correlated dimension factors showed an acceptable fit with $\chi^{2}(80)=104.01, \chi^{2} / d f=1.30$, $p=.037$, CFI $=.93$, TLI $=.91$, RMSEA $=.04$, and $\mathrm{SRMR}=.05$, which is comparable to the fit reported for the personality-based interview by Van Iddekinge et al. (2005), $\chi^{2}(26)=33.48, \chi^{2} / d f=1.29$, CFI $=.93$, and RMSEA $=.06 .{ }^{1}$ In addition, we tested two alternative measurement models. In the first alternative measurement model, all interview questions loaded on one general interview factor (i.e., a model typically found to represent interview ratings; Krajewski, Goffin, McCarthy, Rothstein \& Johnston, 2006). However, this model did not show an acceptable fit, $\chi^{2}(90)=155.60$, $\chi^{2} / d f=1.73, p<.001, \mathrm{CFI}=.81, \mathrm{TLI}=.78, \mathrm{RMSEA}=.06$, and SRMR $=.06$. The second alternative measurement model specified the Big Five as separate but correlated dimension factors and a general interview factor (which is similar to a common method factor). However, this model did not converge. In sum, CFA results demonstrated that the hypothesized model with the Big Five as distinct but correlated factors (and without an additional method/interview factor) showed the best admissible fit and supported Hypothesis 1 concerning the interviews' construct-related validity.

In addition, we conducted correlational multitraitmultimethod (MTMM) analyses (Campbell \& Fiske, 1959) to compare the structure of interview ratings to findings from previous interview studies. The average correlation between the same traits assessed by different methods (i.e., by different interview questions) was .26 (monotrait-heteromethod correlation; convergent validity), and the average correlation of different traits assessed by different interview questions was .15 (heterotrait-heteromethod correlation; discriminant validity). Hence, the average convergent validity coefficient was descriptively higher than the average discriminant validity coefficient. This result speaks in favor of the internal constructrelated validity of the present interview when compared with results from previous studies: Previous interview studies found convergent validity coefficients between different interview questions assessing the same constructs to be relatively small, .09 and .05 (both in Huffcutt, Weekley, Wiesner, Degroot \& Jones, 2001b), .19 (Van Iddekinge, Raymark, Eidson Jr. \& Attenweiler, 2004), and .26 (Klehe, König, Richter, Kleinmann \& Melchers, 2008), and to be descriptively smaller than discriminant validity coefficients, .17 and .09 (both in Huffcutt, Weekley, et al., 2001b), 32. (Van Iddekinge et al., 2004), and .41 (Klehe et al., 2008).

As supplementary analysis, we further investigated construct-related validity by examining how personality-based

\footnotetext{
${ }^{1}$ Please note that Van Iddekinge et al. (2005) did not find support for a factor model reflecting their originally intended interview dimensions because the correlation between two of their dimensions exceeded unity. The fit mentioned here refers to their modified model that specifies only two out of the original three interview dimensions.
} 


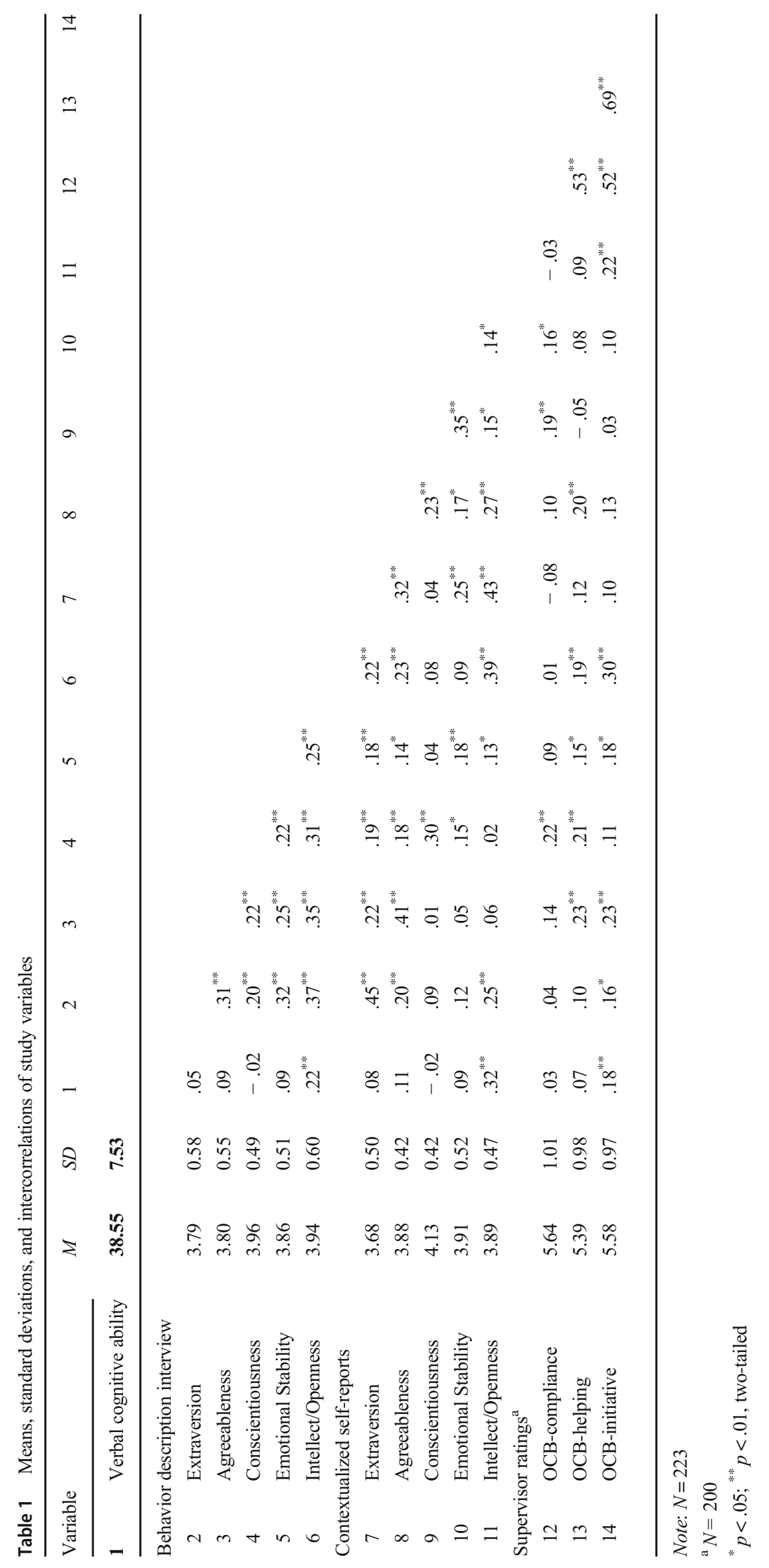


interview ratings correspond to contextualized personality selfreports. Correlational MTMM analyses showed that the average correlation for the same traits assessed by different methods (i.e., by the personality-based interview and the personality selfreport) was .34 (monotrait-heteromethod correlation; convergent validity) and the average correlation for the same methods used to assess different traits was .26 (heterotraitmonomethod correlation; discriminant validity). Hence, the average convergent validity coefficient was descriptively higher than the average discriminant validity coefficient. ${ }^{2}$ This speaks for the external construct-related validity of the present interview and stands in contrast to results from previous interview studies that used ratings of individual interview dimensions: Previous interview studies found convergent validity coefficients between individual interview dimensions and questionnaire-based measures assessing the same constructs to be small, .12 (applicant condition in Van Iddekinge et al., 2005) and .21 (Allen et al., 2004), and to be descriptively smaller than discriminant validity coefficients, .50 (applicant condition in Van Iddekinge et al., 2005) and .70 (Allen et al., 2004).

\section{Predicting OCB: Criterion-related validity of interview ratings}

Hypothesis 2 posited that interview ratings of Conscientiousness would predict OCB-compliance over and above the other Big Five traits assessed in the interview. As can be seen in Table 2, Conscientiousness explained a significant proportion of variance in OCB-compliance beyond the other Big Five personality traits, $\Delta R^{2}=.04, F(1,194)=9.13, p=.003$. When including all Big Five traits as predictors of interviewees' OCB-compliance, only Conscientiousness was significant, $\beta=.22, t(199)=3.02$, $p=.003$ (see Table 2). In addition, we conducted relative weights analyses using the relaimpo package for the $\mathrm{R}$ environment (Grömping, 2006) to determine the relative contribution of each Big Five trait towards explaining variance in OCB-compliance. Relative weights analysis is especially useful when multiple predictors are intercorrelated (Johnson, 2000), which is usually the case with interview dimension ratings. Results yielded that $66.8 \%$ of the variance that interview ratings of personality traits

\footnotetext{
${ }^{2}$ In addition, we conducted an MTMM CFA across personality-based interview ratings and contextualized personality self-reports to estimate the amount of variance in personality ratings that was attributable to trait factors (i.e., the Big Five personality traits) versus method factors (i.e., the structured interview and contextualized self-report). To calculate this model, we created parcels from the personality self-report. More precisely, we randomly assigned the ten items used to measure each trait to one of three parcels per trait (Little, Cunningham, Shahar \& Widaman, 2002). In summary, fit indices implied modest fit, $\chi^{2} / d f=1.58, p<.001, \mathrm{CFI}=.89, \mathrm{TLI}=.87$, RMSEA $=.05$, and $\mathrm{SRMR}=.08$. Results indicated that average factor loadings were .49 for trait factors (with average loadings ranging from .27 for Emotional Stability to .59 for Extraversion) and .38 for method factors (with average loadings being .25 for interview ratings and .67 for self-reports). Factor loadings imply that $23.6 \%$ of the variance in personality ratings was explained by trait factors and $14.2 \%$ of the variance in personality ratings was explained by method factors.
}

explained in OCB-compliance is attributable to Conscientiousness, whereas the other traits explained between 0.8 and $22.0 \%$ of the variance. As such, Hypothesis 2 was supported.

Hypothesis 3 stated that interview ratings of Agreeableness would predict OCB-helping over and above the other Big Five traits assessed in the interview. Results showed that Agreeableness explained a significant proportion of variance in OCB-helping beyond the other Big Five personality traits, $\Delta R^{2}=.02, F(1,194)=5.20, p=.024$ (see Table 2). When including all Big Five traits as predictors of interviewees' OCBhelping, only Agreeableness was a significant predictor, $\beta=.17$, $t(199)=2.28, p=.024$. Relative weights analysis demonstrated that $38.0 \%$ of the variance that personality traits explained in OCB-helping is attributable to Agreeableness, whereas the other traits explained between 2.8 and $29.3 \%$ of the variance. Based on these results, Hypothesis 3 was supported.

Hypothesis 4 posited that interview ratings of Intellect/ Openness would predict OCB-initiative over and above the other Big Five traits assessed in the interview. Table 2 shows that Intellect/Openness explained a significant proportion of variance in OCB-initiative beyond the other Big Five personality traits, $\Delta R^{2}=.04, F(1,194)=8.73, p=.004$. When including all Big Five traits as predictors of interviewees' OCB-initiative, only Intellect/Openness was significant, $\beta=.23, t(199)=2.96$, $p=.004$. Relative weights analysis further showed that $51.4 \%$ of the variance that personality traits explained in OCBinitiative is attributable to Intellect/Openness, whereas the other traits explained between 3.0 and $25.7 \%$ of the variance. Hence, Hypothesis 4 was supported.

Hypotheses $5 \mathrm{a}$ to $5 \mathrm{c}$ predicted that interview ratings of Conscientiousness, Agreeableness, and Intellect/Openness would explain a significant proportion of variance in OCBcompliance, OCB-helping, and OCB-initiative over and above verbal cognitive ability and the contextualized selfreports of the respective personality traits. In support of Hypotheses $5 \mathrm{a}$ to $5 \mathrm{c}$, hierarchical regression analyses revealed that interview ratings of Conscientiousness explained a significant proportion of variance in OCB-compliance beyond interviewees' verbal cognitive ability and contextualized selfreport of Conscientiousness, $\Delta R^{2}=.031, F(1,196)=6.55$, $p=.011$. Interview ratings of Agreeableness explained a significant proportion of variance in OCB-helping beyond interviewees' verbal cognitive ability and contextualized selfreport of Agreeableness, $\Delta R^{2}=.025, F(1,196)=5.25$, $p=.023$. Finally, interview ratings of Intellect/Openness explained a significant proportion of variance in OCB-initiative beyond interviewees' verbal cognitive ability and contextualized self-report of Intellect/Openness, $\Delta R^{2}=.047, F(1$, 196) $=10.31, p=.002$. In each case, personality self-reports became non-significant when personality-based interview ratings as predictors of OCB were included. Results are presented in Table 3. Conversely, personality self-reports did not 
Table 2 Relative weights analyses of OCB-compliance, OCB-helping, and OCB-initiative regressed on interview ratings of the Big Five personality traits

\begin{tabular}{|c|c|c|c|c|c|c|c|}
\hline Variables & $B$ & $S E B$ & $\beta$ & $R W$ & $\% R W$ & $R^{2}$ & $\Delta R^{2}$ \\
\hline \multicolumn{8}{|l|}{ OCB-compliance } \\
\hline Step 1 & & & & & & .024 & \\
\hline Extraversion & -0.02 & 0.14 & -.01 & .001 & 2.2 & & \\
\hline Agreeableness & 0.26 & 0.14 & .14 & .017 & 71.6 & & \\
\hline Emotional Stability & 0.13 & 0.15 & .07 & .005 & 22.2 & & \\
\hline Intellect/Openness & -0.08 & 0.13 & -.05 & .001 & 4.0 & & \\
\hline Step 2 & & & & & & $.068^{*}$ & $.044^{* *}$ \\
\hline Extraversion & -0.03 & 0.14 & -.02 & .001 & 0.8 & & \\
\hline Agreeableness & 0.23 & 0.14 & .13 & .015 & 22.0 & & \\
\hline Conscientiousness & 0.46 & 0.15 & $.22^{* *}$ & .046 & 66.8 & & \\
\hline Emotional Stability & 0.08 & 0.15 & .04 & .004 & 5.4 & & \\
\hline Intellect/Openness & -0.16 & 0.13 & -.10 & .003 & 5.0 & & \\
\hline \multicolumn{8}{|l|}{ OCB-helping } \\
\hline Step 1 & & & & & & $.068^{* *}$ & \\
\hline Extraversion & -0.02 & 0.13 & -.01 & .003 & 4.4 & & \\
\hline Conscientiousness & 0.31 & 0.15 & $.15^{*}$ & .030 & 43.9 & & \\
\hline Emotional Stability & 0.16 & 0.14 & .08 & .012 & 17.8 & & \\
\hline Intellect/Openness & 0.21 & 0.13 & .13 & .023 & 34.0 & & \\
\hline Step 2 & & & & & & $.092^{* *}$ & $.024^{*}$ \\
\hline Extraversion & -0.07 & 0.13 & -.04 & .003 & 2.8 & & \\
\hline Agreeableness & 0.31 & 0.14 & $.17^{*}$ & .035 & 38.0 & & \\
\hline Conscientiousness & 0.29 & 0.15 & .14 & .027 & 29.3 & & \\
\hline Emotional Stability & 0.12 & 0.14 & .06 & .010 & 10.5 & & \\
\hline Intellect/Openness & 0.15 & 0.13 & .09 & .018 & 19.4 & & \\
\hline \multicolumn{8}{|l|}{ OCB-initiative } \\
\hline Step 1 & & & & & & $.073^{* *}$ & \\
\hline Extraversion & 0.10 & 0.13 & .06 & .012 & 16.4 & & \\
\hline Agreeableness & 0.31 & 0.13 & $.18^{*}$ & .038 & 51.9 & & \\
\hline Conscientiousness & 0.08 & 0.14 & .04 & .005 & 6.9 & & \\
\hline Emotional Stability & 0.19 & 0.14 & .10 & .018 & 24.8 & & \\
\hline Step 2 & & & & & & $.113^{* *}$ & $.040^{* *}$ \\
\hline Extraversion & 0.00 & 0.13 & .00 & .008 & 7.1 & & \\
\hline Agreeableness & 0.23 & 0.13 & .13 & .029 & 25.7 & & \\
\hline Conscientiousness & 0.00 & 0.14 & .00 & .003 & 3.0 & & \\
\hline Emotional Stability & 0.16 & 0.14 & .08 & .014 & 12.8 & & \\
\hline Intellect/Openness & 0.37 & 0.12 & $.23^{* *}$ & .058 & 51.4 & & \\
\hline
\end{tabular}

Note: $N=200$

$R W$ relative weights of predictors summing up to $R^{2}, \% R W$ percentages of relative weights

${ }^{*} p<.05 ;{ }^{* *} p<.01$, two-tailed

explain a significant proportion of variance in OCB beyond personality-based interview ratings (when entering personality-based interview ratings first and personality selfreports second into the regression equation). Based on these findings, Hypotheses 5a to 5c concerning the interviews' incremental validity were supported.

In addition, to determine the impact of interview length, we explored the interview's criterion-related and incremental validity using shortened versions of the personality-based interview. Specifically, we tested Hypotheses 2 to 5 measuring each personality traits with (a) one interview question per personality trait (i.e., the one with the highest factor loading) and (b) two interview questions per personality trait (i.e., ratings averaged across the two interview questions with the highest factor loadings). In line with classical test theory (e.g., Gulliksen, 1950), results showed that the interview's criterion-related and incremental validity increases with the number of interview questions being used to measure each personality trait. The magnitude of correlations between personality predictors (i.e., Conscientiousness, Agreeableness, and Intellect/Openness) and their corresponding types of OCB (i.e., OCB-compliance, OCB-helping, and OCB-initiative) ranged from $r=.15(p=.032)$ to $r=.27(p<.001)$ when using one interview question per personality trait, from $r=.19$ 
Table 3 Relative weights analyses of OCB-compliance, OCB-helping, and OCB-initiative regressed on verbal cognitive ability and on self-reports and interview ratings of Conscientiousness, Agreeableness, and Intellect/Openness

\begin{tabular}{|c|c|c|c|c|c|c|c|}
\hline Variables & $B$ & $S E B$ & $\beta$ & $R W$ & $\% R W$ & $R^{2}$ & $\Delta R^{2}$ \\
\hline \multicolumn{8}{|l|}{ OCB-compliance } \\
\hline Step 1 & & & & & & $.036^{*}$ & \\
\hline Verbal cognitive ability & 0.00 & 0.01 & .04 & .001 & 3.0 & & \\
\hline Self-report of Conscientiousness & 0.45 & 0.17 & $.19^{* * *}$ & .035 & 97.0 & & \\
\hline Step 2 & & & & & & $.067^{* * *}$ & $.031^{*}$ \\
\hline Verbal cognitive ability & 0.01 & 0.01 & .04 & .001 & 1.9 & & \\
\hline Self-report of Conscientiousness & 0.32 & 0.18 & .14 & .025 & 37.8 & & \\
\hline Interview rating of Conscientiousness & 0.39 & 0.15 & $.19^{*}$ & .040 & 60.2 & & \\
\hline \multicolumn{8}{|l|}{ OCB-helping } \\
\hline Step 1 & & & & & & $.044^{*}$ & \\
\hline Verbal cognitive ability & 0.01 & 0.01 & .05 & .004 & 9.3 & & \\
\hline Self-report of Agreeableness & 0.45 & 0.16 & $.20^{* *}$ & .040 & 90.7 & & \\
\hline Step 2 & & & & & & $.069^{* * *}$ & $.025^{*}$ \\
\hline Verbal cognitive ability & 0.01 & 0.01 & .04 & .003 & 4.6 & & \\
\hline Self-report of Agreeableness & 0.29 & 0.18 & .12 & .027 & 38.7 & & \\
\hline Interview rating of Agreeableness & 0.31 & 0.14 & $.18^{*}$ & .039 & 56.7 & & \\
\hline \multicolumn{8}{|l|}{ OCB-initiative } \\
\hline Step 1 & & & & & & $.062^{* *}$ & \\
\hline Verbal cognitive ability & 0.02 & 0.01 & .12 & .023 & 37.2 & & \\
\hline Self-report of Intellect/Openness & 0.37 & 0.15 & $.18^{*}$ & .039 & 62.8 & & \\
\hline Step 2 & & & & & & $.109^{* * *}$ & $.047^{* * *}$ \\
\hline Verbal cognitive ability & 0.01 & 0.01 & .10 & .018 & 16.9 & & \\
\hline Self-report of Intellect/Openness & 0.19 & 0.15 & .10 & .026 & 23.6 & & \\
\hline Interview rating of Intellect/Openness & 0.38 & 0.12 & $.23^{* *}$ & .065 & 59.5 & & \\
\hline
\end{tabular}

Note: $N=200$

$R W$ relative weights of predictors summing up to $R^{2}, \% R W$ percentages of relative weights

${ }^{*} p<.05 ;{ }^{* *} p<.01$, two-tailed

$(p=.008)$ to $r=.28(p<.001)$ when using two interview questions per personality trait, and from $r=.22(p=.002)$ to $r=.30$ $(p<.001)$ when using the original three interview questions per personality trait. In the present sample, Conscientiousness and Agreeableness had to be measured with at least two interview questions to explain a significant proportion of variance in OCB-compliance and OCB-helping over and above personality self-reports and verbal cognitive ability, whereas Intellect/Openness could be assessed with just one interview question to explain a significant proportion of variance in OCB-initiative. Hence, using a shortened version of the personality-based interview will suffice, but it will also come at the cost of slightly reduced criterion-related validity.

Hypotheses $6 \mathrm{a}$ to $6 \mathrm{c}$ predicted that interview ratings of Conscientiousness, Agreeableness, and Intellect/Openness would mediate the relationships between self-reports of these traits with OCB-compliance, OCB-helping, and OCB-initiative, respectively. We tested these hypotheses applying a bootstrapping method with 20,000 samples (see Preacher \& Hayes, 2008) using the mediation package for the R environment (Tingley, Yamamoto, Hirose, Keele \& Imai, 2014). As can be seen in Table 4, indirect effects (mediation effects) were significant for predicting OCB-compliance, $B=0.13$ (95\% CI $=0.03,0.28)$, predicting OCB-helping, $B=0.17$ (95\% CI $=0.01,0.37)$, and predicting OCB-initiative, $B=$
$0.20(95 \% \mathrm{CI}=0.06,0.37)$, while direct effects were non-significant. Hence, Hypotheses $6 \mathrm{a}$ to $6 \mathrm{c}$ were supported.

\section{Discussion}

By introducing a personality-based job interview for predicting OCB, our study makes several contributions to the literature. First, our findings demonstrate that interview ratings of specific Big Five personality traits are - to a certain extent - predictive of different types of OCB. This helps to better understand how to select employees for specific citizenship behaviors. For example, results imply that employers may focus on assessing Intellect/Openness in their job interviews if they are specifically looking for employees who are more likely to take initiative in changing and advancing the organization. Second, our findings reveal that all Big Five personality traits can be validly measured using structured interview questions, which goes beyond previous research on assessing personality constructs in the job interview (Van Iddekinge et al., 2005). Third, results show that ratings from a personality-based interview explain some variance in OCB over and above a verbal cognitive ability test and a contextualized personality self-report measure. This suggests that personality-based interviews might have potential to outweigh parts of their costs when compared to other measures (see also 
Table 4 Bootstrapping mediation analyses of OCB-compliance, OCB-helping, and OCB-initiative regressed on self-reports and interview ratings of Conscientiousness, Agreeableness, and Intellect/Openness

\begin{tabular}{lccc}
\hline Model & Estimate & $95 \%$ CI & $p$ \\
\hline Self-reported Conscientiousness $\rightarrow$ interview ratings of Conscientiousness $\rightarrow$ OCB-compliance & {$[0.03,0.28]$} & {$[-0.04,0.66]$} & .009 \\
Indirect effect & 0.13 & {$[0.13,0.77]$} & .056 \\
Direct effect & 0.32 & & .006 \\
Total effect & 0.45 & {$[0.01,0.37]$} & \\
Self-reported Agreeableness $\rightarrow$ interview ratings of Agreeableness $\rightarrow$ OCB-helping & {$[-0.10,0.70]$} & .037 \\
Indirect effect & 0.17 & {$[0.11,0.83]$} & .147 \\
Direct effect & 0.30 & .011 \\
Total effect & 0.47 & {$[0.06,0.37]$} & \\
Self-reported Intellect/Openness $\rightarrow$ interview ratings of Intellect/Openness $\rightarrow$ OCB-initiative & .003 \\
Indirect effect & 0.20 & {$[-0.05,0.56]$} & .101 \\
Direct effect & 0.25 & {$[0.14,0.78]$} & .003 \\
Total effect & 0.45 & \\
\hline
\end{tabular}

Note: $N=200$

CI confidence interval

Barrick et al., 2000; Macan, 2009; Van Iddekinge et al., 2005). Fourth, findings showed that interview ratings mediated the relationship between self-reported personality traits and corresponding forms of OCB. This implies that personality traits can manifest in employees' answers to interview questions and that the situation-specific thoughts, feelings, and behaviors that interviewees report in the interview provide some valid information as to whether they are likely to engage in different forms of OCB.

\section{Theoretical implications}

This study adds insights to three different topic areas: dispositional predictors of OCB, personality assessment in selection settings, and the design of structured job interviews. Contributing to research on dispositional predictors of OCB, our findings highlight the benefits of making specific predictions about which personality trait best predicts which type of OCB. Previous research connecting the Big Five personality traits with OCB has often been limited to investigating the role of Conscientiousness and Agreeableness, thereby excluding the predictive role that other traits, like Intellect/Openness, can have (e.g., Ilies et al., 2009; Morgeson, Reider \& Campion, 2005; Organ \& Ryan, 1995; Venkataramani \& Dalal, 2007; Wang \& Bowling, 2016). In contrast, the present study included all Big Five personality traits in the analyses, compared two different methods for assessing these personality traits (i.e., interview ratings and self-reports), assessed three specific types of OCB via a third source (i.e., supervisor ratings), and specifically examines the relationship of personality traits and OCB in a simulated selection context. A relatively stable finding, regardless of whether personality traits were assessed with an interview or with a self-report, is that Conscientiousness is most central to predicting OCBcompliance, Agreeableness is most relevant to predicting OCB-helping, and Intellect/Openness is the most important Big Five trait for predicting OCB-initiative.

Contributing to research on personality assessment in selection settings, our results imply that personality-based interview ratings capture criterion-relevant information that a contextualized personality self-report and a cognitive ability measure focusing on verbal reasoning do not capture. In the present study, personality-based interview ratings correlated significantly with self-reports of the same personality constructs and, at the same time, explained variance in OCB beyond self-reports of the same personality constructs and verbal cognitive ability. Hence, personality-based interview ratings share some variance with personality self-reports and also capture additional information on applicants' personality which helps to predict OCB.

These findings match theoretical underpinnings from the trait-identity-reputation model (McAbee \& Connelly, 2016) that considers how the source of information (e.g., the individual, co-workers of the individual, or any other raters) can affect the accuracy and validity of personality judgments. The model distinguishes between variance in personality judgments that is uniquely attributable to self-perceptions of an individuals' personality (i.e., 'identity'), others' perceptions of an individual's personality (i.e., 'reputation'), and the actual underlying personality trait defined as the consensus of these different perspectives (McAbee \& Connelly, 2016). Within this framework, personality-based interview ratings might be regarded as a special form of others' perceptions of an applicant's personality: Interviewers, who have zero acquaintance with the applicant (i.e., strangers), rate applicants' personality based on applicants' self-descriptions of their feelings, 
thoughts, and behaviors in different situations. Thus, interview ratings contain information on how applicants see themselves and on how interviewers perceive and evaluate applicant's self-views. Therefore, interview ratings could potentially be better indicators of the underlying personality traits (that are defined as consensus from different perspectives) than mere self-reports.

Contributing to job interview research, our findings demonstrate that structured interview questions can be developed to assess established personality constructs and that assessing such well-defined constructs facilitates the construct-related validity of structured interviews (see Hamdani et al., 2014). Selection researchers have repeatedly stated that one of the major challenges in interview research remains to provide construct-related validity evidence (see Hamdani et al., 2014; Klehe et al., 2008; Macan, 2009; Ployhart, 2006; Raymark \& Van Iddekinge, 2013; Van Iddekinge et al., 2004). As proposed in a theoretical model by Hamdani et al. (2014), this problem can be addressed by first identifying the criteria one would like to predict and by then theoretically matching these criteria with established, carefully defined, and conceptually distinct predictor constructs that are to be assessed in the interview. The present study followed this approach and presents promising results. Specifically, we found that a factor model specifying only the originally intended interview dimensions as latent factors actually fits the data of an interview administered in a (simulated) selection context. Thus, our findings suggest that choosing well-defined psychological constructs, such as the Big Five personality traits, as interview dimensions is a fruitful approach for developing construct-valid interviews.

\section{Implications for practice}

Given the beneficial effects of OCB on organizational effectiveness (e.g., Podsakoff et al., 2009), our study implies that organizations could benefit from using personality-based job interviews to identify organizational citizens. The most relevant implication is that selection practitioners can use the structured interview questions developed in this study as a blueprint to develop interview questions for selecting employees with a propensity to engage in OCB-compliance, OCB-helping, and OCB-initiative. This will require adapting the interview questions from this study to the respective job. A feasible approach might be to use information gathered from a job analysis to adapt (a) the organizational context described in interview questions and (b) the behavioral anchors so that they refer to behaviors fitting with the demands of the job.

In practice, $\mathrm{OCB}$ is not the only criterion on which selection decision would or should be based (see also Organ et al., 2011). Hence, it might be of interest to selection practitioners to use personality-based interview questions for predicting OCB in addition to traditional skill-based interview questions for predicting task performance. Specifically, we recommend adding the three interview questions for measuring each OCBpredictor trait (i.e., Conscientiousness, Agreeableness, and Intellect/Openness) if possible. This is because our additional analyses revealed that measuring OCB-predictor traits with fewer interview questions limits the criterion-related validity of the personality-based interview. Using three interview questions per OCB-predictor (resulting in nine interview questions in total) will take at minimum about $18 \mathrm{~min}$ of interviewing in addition to the time required for a skill-based interview.

Going beyond the prediction of OCB, there has been an extensive debate about how to assess personality in selection contexts (e.g., Morgeson et al., 2007; Ones et al., 2007). Although the job interview has explicitly been proposed as an alternative personality measure (Barrick et al., 2000; Levashina et al., 2014; Raymark \& Van Iddekinge, 2013; Van Iddekinge et al., 2005), this study is first to provide both construct-related and initial criterion-related evidence for a structured interview designed to assess the Big Five personality traits. Our findings imply that practitioners can use interview questions to validly assess personality in selection settings (with the purpose of predicting different kinds of criteria such as person-group fit, job satisfaction, training success, etc.), which seems especially relevant given that job interviews are an integral part to standard selection procedures (Di Milia, 2004; König et al., 2010; Levashina et al., 2014).

\section{Limitations}

Of course, this study is not without limitations. First and foremost, interviewees were not actual applicants. Instead, they were interviewed for a fictitious job in a simulated selection setting. Therefore, interviewees might have been less motivated to perform well in the interview as compared to their performance during an actual job interview. With this limitation in mind, we still chose to conduct the study in a simulated setting so that we could have control over the information on which interviewers base their personality ratings (see also the study design in Barrick et al., 2000; Klehe et al., 2008; Swider et al., 2016; Van Iddekinge et al., 2005). Although interviewees participated voluntarily in this study to receive valid performance feedback that would help them with future job applications, their motivation to perform well would presumably still be high. In fact, our data indicated that interviewees mostly behaved as if they were in an actual selection process and that the interview was criterion valid, which might lower concerns about the generalizability of results.

A second limitation is the heterogeneity of the sample in the present study. Interviewees were from different organizations and held a variety of jobs. Hence, OCB ratings might not be fully comparable across different interviewees, given that OCBs can depend on the organizational context and specific work environment (e.g., on job autonomy, job meaning, and 
on the quality of social exchange relationships at the workplace; Kamdar \& Van Dyne, 2007; Liguori, McLarty \& Muldoon, 2013). At the same time, the heterogeneity of the sample might speak for the generalizability of the present findings across different kinds of jobs and work environments.

Third and relatedly, the focal relationships between interview ratings of personality traits and supervisor ratings of OCBs were only moderate ranging from $r=.22$ to $r=.30$. These effect sizes can be categorized as small to medium (Bosco, Aguinis, Singh, Field \& Pierce, 2015; Cohen, 1992) and are slightly lower than uncorrected estimates reported in the latest meta-analyses on the validity of medium to highly structured job interviews ranging from $\bar{r}=.25$ to $\bar{r}=.36$ (Huffcutt et al., 2014; Thorsteinson, 2018). One explanation may be the heterogeneity of the present sample (i.e., interviewees held different jobs and interview questions were not tailored to meet unique demands of these specific jobs). An alternative explanation might be that structured interviews could work slightly better for predicting task performance (which has been a focal criterion in previous interview studies; Thorsteinson, 2018) as compared to predicting $\mathrm{OCB}$, but more research is needed to test this assumption.

Finally, intercorrelations between interview ratings and personality self-reports found in the present study can be classified as modest to moderate (ranging from $r=.18$ to $r=.45$ ). An explanation for this might be that structured interviews and self-reports differ substantially with regard to several method factors (Heimann and Ingold, 2017; Lievens \& Sackett, 2017). For example, they differ with regard to (1) the person providing the rating (trained interviewer versus untrained interviewee/applicant), (2) their stimulus formats (verbal interview questions versus written questionnaire items), and (3) their level of contextualization (descriptions of specific situations versus more generic items). This might limit expectations about the convergence of structured interviews and self-reports as each uses a different measurement approach. In line with, and similar to, the present study, previous interview research found modest relationships between traditional job interviews and personality self-reports (Roth et al., 2005; Salgado \& Moscoso, 2002).

\section{Directions for future research}

To increase our understanding of how to best predict OCB in job interviews, future research may directly compare interview questions assessing personality traits with interview questions designed for assessing OCBs. So far, previous studies assessing OCBs with behavior description interview questions were only partly successful (Allen et al., 2004; Latham \& Skarlicki, 1995). An advantage of personality-based interview questions over OCB-based interview questions might be that personality traits are supposed to be more stable predictors across various situations as opposed to OCBs (Cohen, Ben-Tura \& Vashdi, 2012; Fassina, Jones \& Uggerslev,
2008). In addition, it might be more common and legally accepted to assess personality traits in selection settings (e.g., Dilchert, Ones \& Krueger, 2019), whereas the conditions are less clear when it comes to explicitly assessing OCBs in a selection context (for an overview see Organ et al., 2011). However, more research is needed to understand whether and how the criterion-related validity of personalitybased and OCB-based interview questions differs.

Relatedly, research is needed to explore how interview questions that were originally designed to predict OCB relate to task performance. This refers to the question of whether there is a trade-off between OCB and task performance. It is possible that employees who dedicate a substantial amount of their resources to OCBs will have less capacity for demonstrating high levels of task performance or will even engage in counterproductive work behavior to compensate for their efforts (e.g., Bolino, Klotz, Turnley \& Harvey, 2013). What speaks against a trade-off between predicting OCB and predicting task performance by the same interview questions is that, conceptually, OCBs are thought to create an environment that enables task performance (Organ, 1997), and empirically, previous research has found strong relationships between employees' OCB and task performance (Hoffman et al., 2007). Hence, more research is needed to investigate whether selecting organizational citizens would also result in the selection of high performers.

\section{Conclusion}

OCB goes beyond the completion of individual work tasks and can determine how well employees function together and form a successful organization. Yet, in the context of personnel selection, our means for identifying those employees who are willing to go the extra mile have been limited. In this context, the present study demonstrates that a structured job interview assessing the Big Five personality traits is a suitable measure for predicting different types of OCB. Thus, we encourage practitioners to use carefully developed and job-related interview questions for selecting organizational citizens, and we propose to selection researchers to further expand the criterion domain when validating new selection instruments - by considering $\mathrm{OCB}$, as well as other relevant criterion constructs (i.e., employee well-being and commitment) in addition to task performance.

Acknowledgements Open access funding provided by University of Zurich.

Funding The study reported in this paper was supported by a grant from the Swiss National.

Science Foundation (grant number 146039). We thank Ute Klehe for her helpful comments on an earlier version of the manuscript, and we thank Alexandra Garcia, Severina Vischer, Peider Fatzer, and Corina Baumgartner who helped collecting the data for this study. 


\section{Appendix 1. Example behavior description interview question for extraversion}

\footnotetext{
"Sometimes you meet a lot of new people. Think of a situation where you participated in a oneor two-day training or workshop and where you did not know the other participants, but some of them seemed very friendly. Please describe exactly how you perceived this situation and what you did in this situation to interact with the other participants"

Notes:

Dimension: Extraversion
5 Feels enthusiastic about the opportunity to make new contacts - actively tries to get to know
as many other participants as possible - makes use of every opportunity to make new
contacts - surrounds himself or herself with different people
3 Perceives the situation as rather interesting - is generally open towards meeting other
participants - needs a reason or a push from others to make new contacts - surrounds himself
or herself with people they know if possible
1 Feels rather uncomfortable in this situation - is reserved towards other participants - does
not try to make new contacts - avoids interactions with others - stays alone or around people
he or she already knows
}

"Sometimes you meet a lot of new people. Think of a situation where you participated in a oneor two-day training or workshop and where you did not know the other participants, but some of them seemed very friendly. Please describe exactly how you perceived this situation and what you did in this situation to interact with the other participants"

\section{Dimension: Extraversion}

5 Feels enthusiastic about the opportunity to make new contacts - actively tries to get to know as many other participants as possible - makes use of every opportunity to make new contacts - surrounds himself or herself with different people

3 Perceives the situation as rather interesting - is generally open towards meeting other participants - needs a reason or a push from others to make new contacts - surrounds himself or herself with people they know if possible

1 Feels rather uncomfortable in this situation - is reserved towards other participants - does not try to make new contacts - avoids interactions with others - stays alone or around people he or she already knows

\section{Appendix 2. Example behavior description interview question for Agreeableness}

"Sometimes we notice that someone else makes a mistake. Think of a situation when a co-worker

made a mistake and you pointed the mistake out to them. Please describe exactly how you perceived this situation and what you did in this situation when you spoke to your co-worker." Notes:

Dimension: Agreeablenss
5 Is very careful in pointing out the mistake - thinks that it is a priority to be considerate
regarding the co-workers' emotions - avoids accusations - points out that everyone makes
mistakes
3 Politely and directly points out the mistake - thinks it is important to be considerate
regarding the co-workers' emotions - does not point out that everyone makes mistakes
sometimes
1 Directly points out the mistake - does not think that it is important to be considerate of the
co-workers' emotions - does not see the emotional side to this situation - makes accusations
or behaves in an insulting manner

"Sometimes we notice that someone else makes a mistake. Think of a situation when a co-worker made a mistake and you pointed the mistake out to them. Please describe exactly how you perceived this situation and what you did in this situation when you spoke to your co-worker."

\section{Dimension: Agreeablenss}

5 Is very careful in pointing out the mistake - thinks that it is a priority to be considerate regarding the co-workers' emotions - avoids accusations - points out that everyone makes mistakes

3 Politely and directly points out the mistake - thinks it is important to be considerate regarding the co-workers' emotions - does not point out that everyone makes mistakes sometimes

1 Directly points out the mistake - does not think that it is important to be considerate of the co-workers' emotions does not see the emotional side to this situation - makes accusations or behaves in an insulting manner 


\section{Appendix 3. Example behavior description interview question for Conscientiousness}

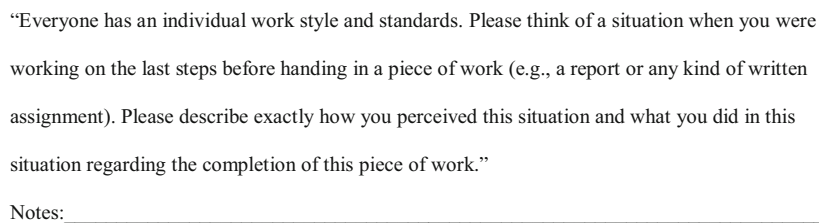

Dimension: Conscientiousness
5 Proceeds in a very systematic and structured manner - thinks that it is most important to
strive for accomplishment - plans ahead and accounts for buffer time - follows a detailed
schedule - double-checks his or her work several times before handing it in
3 Generally proceeds in a systematic and structured manner - thinks that it is important to
strive for accomplishment - plans individual work steps - follows a schedule - double-
checks his or her work roughly before handing it in
1 Proceeds in an unsystematic and unstructured manner - does not think that it is important to
strive for accomplishment - does not plan individual work steps - does not follow a schedule
- does not double-check his or her work before handing it in

"Everyone has an individual work style and standards. Please think of a situation when you were working on the last steps before handing in a piece of work (e.g., a report or any kind of written assignment). Please describe exactly how you perceived this situation and what you did in this situation regarding the completion of this piece of work."

\section{Dimension: Conscientiousness}

5 Proceeds in a very systematic and structured manner thinks that it is most important to strive for accomplishment - plans ahead and accounts for buffer time - follows a detailed schedule - double-checks his or her work several times before handing it in

3 Generally proceeds in a systematic and structured manner - thinks that it is important to strive for accomplishment plans individual work steps - follows a schedule doublechecks his or her work roughly before handing it in

1 Proceeds in an unsystematic and unstructured manner does not think that it is important to strive for accomplishment - does not plan individual work steps - does not follow a schedule - does not double-check his or her work before handing it in
Appendix 4. Example behavior description interview question for Emotional Stability

"Sometimes you have to wait longer than you thought would have to. Think of a situation that ended with you not getting the information that you urgently needed - even though you had asked for this piece of information several times. Please describe exactly how you perceived this situation and what you did in this situation regading the missing information."

Notes:

\begin{tabular}{l}
\hline Dimension: Emotional Stability \\
5 Hardly feels any inner tension regarding the missing information - does not take it \\
personally - behaves in a polite manner towards the responsible person - searches for other \\
ways to get the missing piece of information in a calm and constructive way \\
3 Feels frustrated regarding the missing information - feels treated unfairly - still behaves in a \\
polite manner towards the responsible person - tries to constructively search for other ways \\
to get the missing piece of information \\
1 Feels angry regarding the missing information - feels personally attacked or thinks of \\
himself or herself as a victim - reacts very emotionally and in an uncontrolled manner \\
towards the responsible person - is not able to constructively search for solutions
\end{tabular}

"Sometimes you have to wait longer than you thought would have to. Think of a situation that ended with you not getting the information that you urgently needed - even though you had asked for this piece of information several times. Please describe exactly how you perceived this situation and what you did in this situation regading the missing information."

\section{Dimension: Emotional Stability}

5 Hardly feels any inner tension regarding the missing information - does not take it personally - behaves in a polite manner towards the responsible person - searches for other ways to get the missing piece of information in a calm and constructive way

3 Feels frustrated regarding the missing information - feels treated unfairly - still behaves in a polite manner towards the responsible person - tries to constructively search for other ways to get the missing piece of information

1 Feels angry regarding the missing information - feels personally attacked or thinks of himself or herself as a victim - reacts very emotionally and in an uncontrolled manner towards the responsible person - is not able to constructively search for solutions 


\section{Appendix 5. Example behavior description interview question for Intellect/Openness}

"Some subjects may seem especially interesting. Please think of a situation when you had the opportunity to look into a new subject more deeply than was necessary for completing a task. Please describe exactly how you perceived this situation and what you did in this situation regarding the opportunity to look into the new subject."

Notes:

Dimension: Intellect/Openness
5 Feels enthusiastic about looking deeply into any new subject - is completely open to new
ideas - can inspire and motivate himself or herself to approach new subjects
3 Feels that looking more deeply into certain subjects may be interesting - is willing to open
up to new ideas to a certain extent - can generally be inspired and motivated to take a step
towards new subjects
Hardly feels the need to deeply look into the new subject - is not willing to open up to new
ideas - can hardly be inspired and motivated to take a step towards new subjects

"Some subjects may seem especially interesting. Please think of a situation when you had the opportunity to look into a new subject more deeply than was necessary for completing a task. Please describe exactly how you perceived this situation and what you did in this situation regarding the opportunity to look into the new subject."

\section{Dimension: Intellect/Openness}

5 Feels enthusiastic about looking deeply into any new subject - is completely open to new ideas - can inspire and motivate himself or herself to approach new subjects

3 Feels that looking more deeply into certain subjects may be interesting - is willing to open up to new ideas to a certain extent - can generally be inspired and motivated to take a step towards new subjects

1 Hardly feels the need to deeply look into the new subject is not willing to open up to new ideas - can hardly be inspired and motivated to take a step towards new subjects

Open Access This article is licensed under a Creative Commons Attribution 4.0 International License, which permits use, sharing, adaptation, distribution and reproduction in any medium or format, as long as you give appropriate credit to the original author(s) and the source, provide a link to the Creative Commons licence, and indicate if changes were made. The images or other third party material in this article are included in the article's Creative Commons licence, unless indicated otherwise in a credit line to the material. If material is not included in the article's Creative Commons licence and your intended use is not permitted by statutory regulation or exceeds the permitted use, you will need to obtain permission directly from the copyright holder. To view a copy of this licence, visit http://creativecommons.org/licenses/by/4.0/.

\section{References}

Allen, T. D., Facteau, J. D., \& Facteau, C. L. (2004). Structured interviewing for OCB: Construct validity, faking, and the effects of question type. Human Performance, 17(1), 1-24. https://doi. org/10.1207/S15327043hup1701_1.

Amthauer, R., Brocke, B., Liepmann, D., \& Beauducel, A. (1999). Intelligenz-Struktur-Test 2000 [Intelligence-Structure-Test]. Hogrefe.

Anderson, N., Salgado, J. F., \& Hülsheger, U. R. (2010). Applicant reactions in selection: Comprehensive meta-analysis into reaction generalization versus situational specificity. International Journal of Selection and Assessment, 18(3), 291-304. https://doi.org/10.1111/ j.1468-2389.2010.00512.x.

Anglim, J., Lievens, F., Everton, L., Grant, S. L., \& Marty, A. (2018). HEXACO personality predicts counterproductive work behavior and organizational citizenship behavior in low-stakes and job applicant contexts. Journal of Research in Personality, 77, 11-20. https:// doi.org/10.1016/j.jrp.2018.09.003.

Atkins, P. W. B., \& Wood, R. E. (2002). Self- versus others' ratings as predictors of assessment center ratings: Validation evidence for 360degree feedback programs. Personnel Psychology, 55(4), 871-904. https://doi.org/10.1111/j.1744-6570.2002.tb00133.x.

Barrick, M. R., Patton, G. K., \& Haugland, S. N. (2000). Accuracy of interviewer judgments of job applicant personality traits. Personnel Psychology, 53(4), 925-951. https://doi.org/10.1111/j.1744-6570. 2000.tb02424.x.

Bergman, M. E., Donovan, M. A., Drasgow, F., Overton, R. C., \& Henning, J. B. (2008). Test of Motowidlo et al's (1997) theory of individual differences in task and contextual performance. Human Performance, 21(3), 227-253. https://doi.org/10.1080/ 08959280802137606.

Berry, C. M., Sackett, P. R., \& Landers, R. N. (2007). Revisiting interview-cognitive ability relationships: Attending to specific range restriction mechanisms in meta-analysis. Personnel Psychology, 60(4), 837-874. https://doi.org/10.1111/j.1744-6570.2007.00093.x.

Binnewies, C., Sonnentag, S., \& Mojza, E. J. (2009). Feeling recovered and thinking about the good sides of one's work. Journal of Occupational Health Psychology, 14(3), 243-256. https://doi.org/ 10.1037/a0014933.

Birkeland, S. A., Manson, T. M., Kisamore, J. L., Brannick, M. T., \& Smith, M. A. (2006). A meta-analytic investigation of job applicant faking on personality measures. International Journal of Selection and Assessment, 14(4), 317-335. https://doi.org/10.1111/j.14682389.2006.00354.x.

Blickle, G., Momm, T., Schneider, P. B., Gansen, D., \& Kramer, J. (2009). Does acquisitive self-presentation in personality selfratings enhance validity? Evidence from two experimental field studies. International Journal of Selection and Assessment, 17(2), 142-153. https://doi.org/10.1111/j.1468-2389.2009.00458.x.

Bolino, M. C., Klotz, A. C., Turnley, W. H., \& Harvey, J. (2013). Exploring the dark side of organizational citizenship behavior. Journal of Organizational Behavior, 34(4), 542-559. https://doi. org/10.1002/job.1847.

Borman, W. C., \& Motowidlo, S. J. (1993). Expanding the criterion domain to include elements of contextual performance. In $\mathrm{N}$. Schmitt \& W. C. Borman (Eds.), Personnel selection (pp. 71-98). Jossey-Bass. 
Borman, W. C., \& Motowidlo, S. J. (1997). Task performance and contextual performance: The meaning for personnel selection research. Human Performance, 10(2), 99-109. https://doi.org/10.1207/ s15327043hup1002_3.

Borman, W. C., Penner, L. A., Allen, T. D., \& Motowidlo, S. J. (2001). Personality predictors of citizenship performance. International Journal of Selection and Assessment, 9(1-2), 52-69. https://doi. org/10.1111/1468-2389.00163.

Bosco, F. A., Aguinis, H., Singh, K., Field, J. G., \& Pierce, C. A. (2015). Correlational effect size benchmarks. Journal of Applied Psychology, 100(2), 431-449. https://doi.org/10.1037/a0038047.

Bowling, N. A., \& Burns, G. N. (2010). A comparison of work-specific and general personality measures as predictors of work and nonwork criteria. Personality and Individual Differences, 49(2), 95101. https://doi.org/10.1016/j.paid.2010.03.009.

Campbell, D. T., \& Fiske, D. W. (1959). Convergent and discriminant validation by the multitrait-multimethod matrix. Psychological Bulletin, 56(2), 81-105. https://doi.org/10.1037/h0046016.

Campion, M. A., Palmer, D. K., \& Campion, J. E. (1997). A review of structure in the selection interview. Personnel Psychology, 50(3), 655-702. https://doi.org/10.1111/j.1744-6570.1997.tb00709.x.

Chiaburu, D. S., Oh, I.-S., Berry, C. M., Li, N., \& Gardner, R. G. (2011). The five-factor model of personality traits and organizational citizenship behaviors: A meta-analysis. Journal of Applied Psychology, 96(6), 1140-1166. https://doi.org/10.1037/a0024004.

Cohen, A., Ben-Tura, E., \& Vashdi, D. R. (2012). The relationship between social exchange variables, $\mathrm{OCB}$, and performance: What happens when you consider group characteristics? Personnel Review, 41(6), 705-731. https://doi.org/10.1108/00483481211263638.

Cohen, J. (1992). A power primer. Psychological Bulletin, 112(1), 155159. https://doi.org/10.1037/0033-2909.112.1.155.

Cortina, J. M., \& Luchman, J. N. (2013). Personnel selection and employee performance. In N. W. Schmitt, S. Highhouse, I. B. Weiner, N. W. Schmitt, S. Highhouse, \& I. B. Weiner (Eds.), Handbook of psychology: Industrial and organizational psychology, Vol. 12, 2nd ed. (pp. 143-183). John Wiley \& Sons Inc.

Costa, P. T., \& McCrae, R. R. (1989). The NEO-PI/NEO-FFI manual supplement. Psychological Assessment Resources.

Dalal, R. S. (2005). A meta-analysis of the relationship between organizational citizenship behavior and counterproductive work behavior. Journal of Applied Psychology, 90(6), 1241-1255. https://doi.org/ 10.1037/0021-9010.90.6.1241.

Darr, W., \& Catano, V. M. (2008). Multisource assessments of behavioral competencies and selection interview performance. International Journal of Selection and Assessment, 16(1), 68-72. https://doi.org/ 10.1111/j.1468-2389.2008.00410.x.

Debus, M. E., Greulich, B., König, C. J., \& Kleinmann, M. (2019). Insecure about how to rate your job insecurity? A two-study investigation into time frames applied to job insecurity measures. Occupational Health Science, 3(4), 421-435. https://doi.org/10. 1007/s41542-019-00049-x.

Di Milia, L. (2004). Australian management selection practices: Closing the gap between research findings and practice. Asia Pacific Journal of Human Resources, 42(2), 214-228. https://doi.org/10.1177/ 1038411104045364.

Dilchert, S., Ones, D. S., \& Krueger, R. F. (2019). Personality assessment for work: Legal, I-O, and clinical perspective. Industrial and Organizational Psychology: Perspectives on Science and Practice, 12(2), 143-150. https://doi.org/10.1017/iop.2019.27.

Dudley, N. M., \& Cortina, J. M. (2008). Knowledge and skills that facilitate the personal support dimension of citizenship. Journal of Applied Psychology, 93(6), 1249-1270. https://doi.org/10.1037/ a0012572.

Fassina, N. E., Jones, D. A., \& Uggerslev, K. L. (2008). Meta-analytic tests of relationships between organizational justice and citizenship behavior: Testing agent-system and shared-variance models.
Journal of Organizational Behavior, 29(6), 805-828. https://doi. org/10.1002/job.494.

Freudenthaler, H. H., \& Neubauer, A. C. (2005). Emotional intelligence: The convergent and discriminant validities of intra- and interpersonal emotional abilities. Personality and Individual Differences, 39(3), 569-579. https://doi.org/10.1016/j.paid.2005.02.004.

Goldberg, L. R. (1990). An alternative 'description of personality': The Big-Five factor structure. Journal of Personality and Social Psychology, 59(6), 1216-1229. https://doi.org/10.1037/0022-3514. 59.6.1216.

Goldberg, L. R. (1992). The development of markers for the Big-Five factor structure. Psychological Assessment, 4(1), 26-42. https://doi. org/10.1037/1040-3590.4.1.26.

Gonzalez-Mulé, E., Mount, M. K., \& Oh, I.-S. (2014). A meta-analysis of the relationship between general mental ability and nontask performance. Journal of Applied Psychology, 99(6), 1222-1243. https:// doi.org/10.1037/a0037547.

Graham, J. W. (1986). Principled organizational dissent: A theoretical essay. Research in Organizational Behavior, 8, 1-52.

Grömping, U. (2006). Relative importance for linear regression in R: The package relaimpo. Journal of Statistical Software, 17(1). https://doi. org/10.18637/jss.v017.i01.

Gulliksen, H. (1950). Effect of test length on reliability (general case). In H. Gulliksen (Ed.), Theory of mental tests (pp. 74-87). John Wiley \& Sons Inc. https://doi.org/10.1037/13240-008.

Hamdani, M. R., Valcea, S., \& Buckley, M. R. (2014). The relentless pursuit of construct validity in the design of employment interviews. Human Resource Management Review, 24(2), 160-176. https://doi. org/10.1016/j.hrmr.2013.07.002.

Heimann, A. L., \& Ingold, P. V. (2017). Broadening the scope: Situationspecific personality assessment with behavior description interviews [Peer commentary on the paper "Assessing personality-situation interplay in personnel selection: Towards more integration into personality research" by F. Lievens]. European Journal of Personality, 31(5), 457-459. https://doi.org/10.1002/per.2119.

Hoffman, B. J., Blair, C. A., Meriac, J. P., \& Woehr, D. J. (2007). Expanding the criterion domain? A quantitative review of the OCB literature. Journal of Applied Psychology, 92(2), 555-566. https://doi.org/10.1037/0021-9010.92.2.555.

Hofstee, W. K., de Raad, B., \& Goldberg, L. R. (1992). Integration of the Big Five and circumplex approaches to trait structure. Journal of Personality and Social Psychology, 63(1), 146-163. https://doi.org/ 10.1037/0022-3514.63.1.146.

Hogan, J., Rybicki, S. L., Motowidlo, S. J., \& Borman, W. C. (1998). Relations between contextual performance, personality, and occupational advancement. Human Performance, 11(2-3), 189-207. https://doi.org/10.1207/s15327043hup1102\&3_5.

Hough, L. M., \& Furnham, A. (2003). Use of personality variables in work settings. In W. C. Borman, D. R. Ilgen, \& R. J. Klimoski (Eds.), Handbook of psychology: Industrial and organizational psychology, Vol. 12. (pp. 131-169). Wiley.

Huffcutt, A. I., Conway, J. M., Roth, P. L., \& Stone, N. J. (2001a). Identification and meta-analytic assessment of psychological constructs measured in employment interviews. Journal of Applied Psychology, 86(5), 897-913. https://doi.org/10.1037//0021-9010. 86.5.897

Huffcutt, A. I., Weekley, J. A., Wiesner, W. H., Degroot, T. G., \& Jones, C. (2001b). Comparison of situational and behavior description interview questions for higher-level positions. Personnel Psychology, 54(3), 619-644. https://doi.org/10.1111/j.1744-6570.2001.tb00225.x.

Huffcutt, A. I., Culbertson, S. S., \& Weyhrauch, W. S. (2014). Moving forward indirectly: Reanalyzing the validity of employment interviews with indirect range restriction methodology. International Journal of Selection and Assessment, 22(3), 297-309. https://doi. org/10.1111/ijsa.12078. 
Huffcutt, A. I., Van Iddekinge, C. H., \& Roth, P. L. (2011). Understanding applicant behavior in employment interviews: A theoretical model of interviewee performance. Human Resource Management Review, 21(4), 353-367.

Hülsheger, U. R., Maier, G. W., \& Stumpp, T. (2007). Validity of general mental ability for the prediction of job performance and training success in Germany: A meta-analysis. International Journal of Selection and Assessment, 15(1), 3-18. https://doi.org/10.1111/j. 1468-2389.2007.00363.x.

Hurtz, G. M., \& Donovan, J. J. (2000). Personality and job performance: The Big Five revisited. Journal of Applied Psychology, 85(6), 869879. https://doi.org/10.1037/0021-9010.85.6.869.

Ilies, R., Fulmer, I. S., Spitzmuller, M., \& Johnson, M. D. (2009). Personality and citizenship behavior: The mediating role of job satisfaction. Journal of Applied Psychology, 94(4), 945-959. https:// doi.org/10.1037/a0013329.

Ingold, P. V., Kleinmann, M., König, C. J., \& Melchers, K. G. (2016). Transparency of assessment centers: Lower criterion-related validity but greater opportunity to perform? Personnel Psychology, 69, 467497. https://doi.org/10.1111/peps.12105.

Jackson, D. J. R., Dewberry, C., Gallagher, J., \& Close, L. (2018). A comparative study of practitioner perceptions of selection methods in the United Kingdom. Journal of Occupational and Organizational Psychology, 91(1), 33-56. https://doi.org/10.1111/ joop.12187.

Jansen, A., Lievens, F., \& Kleinmann, M. (2011). Do individual differences in perceiving situational demands moderate the relationship between personality and assessment center dimension ratings? Human Performance, 24(3), 231-250. https://doi.org/10.1080/ 08959285.2011 .580805 .

Janz, T. (1982). Initial comparisons of patterned behavior description interviews versus unstructured interviews. Journal of Applied Psychology, 67(5), 577-580. https://doi.org/10.1037/0021-9010. 67.5.577.

Johnson, J. W. (2000). A heuristic method for estimating the relative weight of predictor variables in multiple regression. Multivariate Behavioral Research, 35(1), 1-19. https://doi.org/10.1207/ S15327906MBR3501_1.

Judge, T. A., Simon, L. S., Hurst, C., \& Kelley, K. (2014). What I experienced yesterday is who I am today: Relationship of work motivations and behaviors to within-individual variation in the five-factor model of personality. Journal of Applied Psychology, 99(2), 199221. https://doi.org/10.1037/a0034485.

Kamdar, D., \& Van Dyne, L. (2007). The joint effects of personality and workplace social exchange relationships in predicting task performance and citizenship performance. Journal of Applied Psychology, 92(5), 1286-1298. https://doi.org/10.1037/0021-9010.92.5.1286.

Klehe, U.-C., König, C. J., Richter, G. M., Kleinmann, M., \& Melchers, K. G. (2008). Transparency in structured interviews: Consequences for construct and criterion-related validity. Human Performance, 21(2), 107-137. https://doi.org/10.1080/08959280801917636.

Kluemper, D. H., DeGroot, T., \& Choi, S. (2013). Emotion management ability: Predicting task performance, citizenship, and deviance. Journal of Management, 39(4), 878-905. https://doi.org/10.1177/ 0149206311407326.

König, C. J., Klehe, U.-C., Berchtold, M., \& Kleinmann, M. (2010). Reasons for being selective when choosing personnel selection procedures. International Journal of Selection and Assessment, 18(1), 17-27. https://doi.org/10.1111/j.1468-2389.2010.00485.x.

Konovsky, M. A., \& Organ, D. W. (1996). Dispositional and contextual determinants of organizational citizenship behavior. Journal of Organizational Behavior, 17(3), 253-266. https://doi.org/10.1002/ (SICI)1099-1379(199605)17:3<253::AID-JOB747>3.0.CO;2-Q.

Koopmans, L., Bernaards, C. M., Hildebrandt, V. H., Schaufeli, W. B., de Vet, H. C. W., \& van der Beek, A. J. (2011). Conceptual frameworks of individual work performance: A systematic review.
Journal of Occupational and Environmental Medicine, 53(8), 856-866. https://doi.org/10.1097/JOM.0b013e318226a763.

Koys, D. J. (2001). The effects of employee satisfaction, organizational citizenship behavior, and turnover on organizational effectiveness: A unit-level, longitudinal study. Personnel Psychology, 54(1), 101114. https://doi.org/10.1111/j.1744-6570.2001.tb00087.x.

Krajewski, H. T., Goffin, R. D., McCarthy, J. M., Rothstein, M. G., \& Johnston, N. (2006). Comparing the validity of structured interviews for managerial-level employees: Should we look to the past or focus on the future? Journal of Occupational and Organizational Psychology, 79(3), 411-432. https://doi.org/10.1348/ 096317905X68790.

Krumm, S., Grube, A., \& Hertel, G. (2013). The Munster work value measure. Journal of Managerial Psychology, 28(5), 532-560. https://doi.org/10.1108/JMP-07-2011-0023.

Latham, G. P., \& Skarlicki, D. P. (1995). Criterion-related validity of the situational and patterned behavior description interviews with organizational citizenship behavior. Human Performance, 8(2), 67-80. https://doi.org/10.1080/08959289509539857.

Lehmann-Willenbrock, N., Grohmann, A., \& Kauffeld, S. (2013). Promoting multifoci citizenship behavior: Time-lagged effects of procedural justice, trust, and commitment. Applied Psychology: An International Review, 62(3), 454-485. https://doi.org/10.1111/j. 1464-0597.2012.00488.x.

LePine, J. A., Erez, A., \& Johnson, D. E. (2002). The nature and dimensionality of organizational citizenship behavior: A critical review and meta-analysis. Journal of Applied Psychology, 87(1), 52-65. https://doi.org/10.1037/0021-9010.87.1.52.

Levashina, J., Hartwell, C. J., Morgeson, F. P., \& Campion, M. A. (2014), The structured employment interview: Narrative and quantitative review of the research literature. Personnel Psychology, 67(1), 241-293. https://doi.org/10.1111/peps.12052.

Lievens, F., De Corte, W., \& Schollaert, E. (2008). A closer look at the frame-of-reference effect in personality scale scores and validity. Journal of Applied Psychology, 93(2), 268-279. https://doi.org/10. 1037/0021-9010.93.2.268

Lievens, F., \& Sackett, P. R. (2017). The effects of predictor method factors on selection outcomes: A modular approach to personnel selection procedures. Journal of Applied Psychology, 102(1), 4366. https://doi.org/10.1037/apl0000160.

Liguori, E. W., McLarty, B. D., \& Muldoon, J. (2013). The moderating effect of perceived job characteristics on the proactive personalityorganizational citizenship behavior relationship. Leadership \& Organization Development Journal, 34(8), 724-740. https://doi. org/10.1108/LODJ-01-2012-0014.

Little, T. D., Cunningham, W. A., Shahar, G., \& Widaman, K. F. (2002). To parcel or not to parcel: Exploring the question, weighing the merits. Structural Equation Modeling, 9(2), 151-173. https://doi. org/10.1207/S15328007SEM0902_1.

Macan, T. (2009). The employment interview: A review of current studies and directions for future research. Human Resource Management Review, 19(3), 203-218. https://doi.org/10.1016/j. hrmr.2009.03.006

Marinova, S. V., Peng, C., Lorinkova, N., Van Dyne, L., \& Chiaburu, D. (2015). Change-oriented behavior: A meta-analysis of individual and job design predictors. Journal of Vocational Behavior, 88, 104-120. https://doi.org/10.1016/j.jvb.2015.02.006.

Maydeu-Olivares, A. (2017). Maximum likelihood estimation of structural equation models for continuous data: Standard errors and goodness of fit. Structural Equation Modeling: A Multidisciplinary Journal, 24(3), 383-394. https://doi.org/10.1080/10705511.2016. 1269606.

McAbee, S. T., \& Connelly, B. S. (2016). A multi-rater framework for studying personality: The trait-reputation-identity model. Psychological Review, 123(5), 569-591. https://doi.org/10.1037/ rev0000035. 
McCrae, R. R., \& Costa, P. T. (2004). A contemplated revision of the NEO Five-Factor Inventory. Personality and Individual Differences, 36(3), 587-596. https://doi.org/10.1016/S01918869(03)00118-1.

McDaniel, M. A., Whetzel, D. L., Schmidt, F. L., \& Maurer, S. D. (1994). The validity of employment interviews: A comprehensive review and meta-analysis. Journal of Applied Psychology, 79(4), 599616. https://doi.org/10.1037/0021-9010.79.4.599.

Morgeson, F. P., Campion, M. A., Dipboye, R. L., Hollenbeck, J. R., Murphy, K., \& Schmitt, N. (2007). Reconsidering the use of personality tests in personnel selection contexts. Personnel Psychology, 60(3), 683-729. https://doi.org/10.1111/j.1744-6570.2007.00089.x.

Morgeson, F. P., Reider, M. H., \& Campion, M. A. (2005). Selecting individuals in team settings: The importance of social skills, personality characteristics, and teamwork knowledge. Personnel Psychology, 58(3), 583-611. https://doi.org/10.1111/j.1744-6570. 2005.655.x.

Mortensen, E. L., Flensborg-Madsen, T., Molbo, D., Fagerlund, B., Christensen, U., Lund, R., Osler, M., \& Avlund, K. (2014). The relationship between cognitive ability and demographic factors in late midlife. Journal of Aging and Health, 26(1), 37-53. https://doi. org $/ 10.1177 / 0898264313508780$.

Motowidlo, S. J., Borman, W. C., \& Schmit, M. J. (1997). A theory of individual differences in task and contextual performance. Human Performance, 10(2), 71-83. https://doi.org/10.1207/ s15327043hup1002_1.

Niehoff, B. P., \& Moorman, R. H. (1993). Justice as a mediator of the relationship between methods of monitoring and organizational citizenship behavior. Academy of Management Journal, 36(3), 527556. https://doi.org/10.2307/256591.

Ones, D. S., Dilchert, S., Viswesvaran, C., \& Judge, T. A. (2007). In support of personality assessment in organizational settings. Personnel Psychology, 60(4), 995-1027. https://doi.org/10.1111/j. 1744-6570.2007.00099.x.

Organ, D. W. (1988). Organizational citizenship behavior: The good soldier syndrome. Lexington Books.

Organ, D. W. (1997). Organizational citizenship behavior: It's construct clean-up time. Human Performance, 10(2), 85-97. https://doi.org/ 10.1207/s15327043hup1002_2.

Organ, D. W., Podsakoff, P. M., \& MacKenzie, S. B. (2006). Organizational citizenship behavior: Its nature, antecedents, and consequences. Sage.

Organ, D. W., Podsakoff, P. M., \& Podsakoff, N. P. (2011). Expanding the criterion domain to include organizational citizenship behavior: Implications for employee selection. In S. Zedeck (Ed.), APA handbook of industrial and organizational psychology, Vol 2: Selecting and developing members for the organization. (pp. 281-323). American Psychological Association. https://doi.org/10.1037/ 12170-010

Organ, D. W., \& Ryan, K. (1995). A meta-analytic review of attitudinal and dispositional predictors of organizational citizenship behavior. Personnel Psychology, 48(4), 775-802. https://doi.org/10.1111/j. 1744-6570.1995.tb01781.x.

Ployhart, R. E. (2006). Staffing in the 21st century: New challenges and strategic opportunities. Journal of Management, 32(6), 868-897. https://doi.org/10.1177/0149206306293625.

Podsakoff, N. P., Whiting, S. W., Podsakoff, P. M., \& Blume, B. D. (2009). Individual- and organizational-level consequences of organizational citizenship behaviors: A meta-analysis. Journal of Applied Psychology, 94(1), 122-141. https://doi.org/10.1037/ a0013079.

Podsakoff, N. P., Whiting, S. W., Podsakoff, P. M., \& Mishra, P. (2011). Effects of organizational citizenship behaviors on selection decisions in employment interviews. Journal of Applied Psychology, 96(2), 310-326. https://doi.org/10.1037/a0020948.
Preacher, K. J., \& Hayes, A. F. (2008). Asymptotic and resampling strategies for assessing and comparing indirect effects in multiple mediator models. Behavior Research Methods, 40(3), 879-891. https:// doi.org/10.3758/BRM.40.3.879.

Raymark, P. H., \& Van Iddekinge, C. H. (2013). Assessing personality in selection interviews. In N. D. Christiansen \& R. P. Tett (Eds.), Handbook of personality at work. Routledge.

Roch, S. G., Woehr, D. J., Mishra, V., \& Kieszczynska, U. (2012). Rater training revisited: An updated meta-analytic review of frame-ofreference training. Journal of Occupational and Organizational Psychology, 85(2), 370-395. https://doi.org/10.1111/j.2044-8325. 2011.02045.x.

Rosseel, Y. (2012). Lavaan: An R package for structural equation modeling. Journal of Statistical Software, 48(2), 1-36. https://doi.org/10. 18637/jss.v048.i02.

Roth, P. L., \& Huffcutt, A. I. (2013). A meta-analysis of interviews and cognitive ability: Back to the future? Journal of Personnel Psychology, 12(4), 157-169. https://doi.org/10.1027/1866-5888/ a000091.

Roth, P. L., Van Iddekinge, C. H., Huffcutt, A. I., Eidson Jr., C. E., \& Schmit, M. J. (2005). Personality saturation in structured interviews. International Journal of Selection and Assessment, 13(4), 261-273. https://doi.org/10.1111/j.1468-2389.2005.00323.x.

Rothstein, M. G., \& Goffin, R. D. (2006). The use of personality measures in personnel selection: What does current research support? Human Resource Management Review, 16(2), 155-180. https://doi. org/10.1016/j.hrmr.2006.03.004.

Sackett, P. R., Lievens, F., Van Iddekinge, C. H., \& Kuncel, N. R. (2017). Individual differences and their measurement: A review of 100 years of research. Journal of Applied Psychology, 102(3), 254-273. https://doi.org/10.1037/apl0000151.

Sackmann, S. A., Eggenhofer-Rehart, P. M., \& Friesl, M. (2009). Sustainable change: Long-term efforts toward developing a learning organization. Journal of Applied Behavioral Science, 45(4), 521549. https://doi.org/10.1177/0021886309346001.

Salgado, J. F. (2016). A theoretical model of psychometric effects of faking on assessment procedures: Empirical findings and implications for personality at work. International Journal of Selection and Assessment, 24(3), 209-228. https://doi.org/10.1111/ijsa.12142.

Salgado, J. F., \& Moscoso, S. (2002). Comprehensive meta-analysis of the construct validity of the employment interview. European Journal of Work and Organizational Psychology, 11(3), 299-324. https://doi.org/10.1080/13594320244000184.

Schmit, M. J., \& Ryan, A. M. (1993). The Big Five in personnel selection: Factor structure in applicant and nonapplicant populations. Journal of Applied Psychology, 78(6), 966-974. https://doi.org/10.1037/ 0021-9010.78.6.966.

Shaffer, J. A., \& Postlethwaite, B. E. (2012). A matter of context: A metaanalytic investigation of the relative validity of contextualized and noncontextualized personality measures. Personnel Psychology, 65(3), 445-493. https://doi.org/10.1111/j.1744-6570.2012.01250.x.

Smith, C. A., Organ, D. W., \& Near, J. P. (1983). Organizational citizenship behavior: Its nature and antecedents. Journal of Applied Psychology, 68(4), 653-663. https://doi.org/10.1037/0021-9010. 68.4.653.

Staufenbiel, T., \& Hartz, C. (2000). Organizational citizenship behavior: Entwicklung und erste Validierung eines Meßinstruments [Organizational citizenship behavior: Development and validation of a measurement instrument]. Diagnostica, 46(2), 73-83. https:// doi.org/10.1026//0012-1924.46.2.73.

Steinmayr, R., \& Amelang, M. (2006). Erste Untersuchungen zur Kriteriums-Validität des I-S-T $2000 \mathrm{R}$ an Erwachsenen beiderlei Geschlechts [First results regarding the criterion validity of the I-ST 2000 R concerning adults of both sexes]. Diagnostica, 52(4), 181188. https://doi.org/10.1026/0012-1924.52.4.181. 
Strobel, M., Tumasjan, A., Spörrle, M., \& Welpe, I. M. (2013). The future starts today, not tomorrow: How future focus promotes organizational citizenship behaviors. Human Relations, 66(6), 829-856. https://doi.org/10.1177/0018726712470709.

Swider, B. W., Barrick, M. R., \& Harris, T. B. (2016). Initial impressions: What they are, what they are not, and how they influence structured interview outcomes. Journal of Applied Psychology, 101(5), 625638. https://doi.org/10.1037/ap10000077.

Tett, R. P., \& Burnett, D. D. (2003). A personality trait-based interactionist model of job performance. Journal of Applied Psychology, 88(3), 500-517. https://doi.org/10.1037/0021-9010. 88.3.500

Thorsteinson, T. J. (2018). A meta-analysis of interview length on reliability and validity. Journal of Occupational and Organizational Psychology, 91(1), 1-32. https://doi.org/10.1111/joop.12186.

Tingley, D., Yamamoto, T., Hirose, K., Keele, L., \& Imai, K. (2014). Mediation: R package for causal mediation analysis. Journal of Statistical Software, 59, 1-38. 10.18637/jss.v059.i05.

Van Iddekinge, C. H., Raymark, P. H., Eidson Jr., C. E., \& Attenweiler, W. J. (2004). What do structured selection interviews really measure? The construct validity of behavior description interviews. Human Performance, 17(1), 71-93. https://doi.org/10.1207/ S15327043HUP1701 4.

Van Iddekinge, C. H., Raymark, P. H., \& Roth, P. L. (2005). Assessing personality with a structured employment interview: Constructrelated validity and susceptibility to response inflation. Journal of Applied Psychology, 90(3), 536-552. https://doi.org/10.1037/00219010.90.3.536.

Van Iddekinge, C. H., Raymark, P. H., Roth, P. L., \& Payne, H. S. (2006). Comparing the psychometric characteristics of ratings of face-toface and videotaped structured interviews. International Journal of Selection and Assessment, 14(4), 347-359. https://doi.org/10.1111/ j.1468-2389.2006.00356.x.

Venkataramani, V., \& Dalal, R. S. (2007). Who helps and harms whom? Relational antecedents of interpersonal helping and harming in organizations. Journal of Applied Psychology, 92(4), 952-966. https:// doi.org/10.1037/0021-9010.92.4.952.

Viswesvaran, C., \& Ones, D. S. (2000). Perspectives on models of job performance. International Journal of Selection and Assessment, 8, 216-226. https://doi.org/10.1111/1468-2389.00151.
Wang, Q., \& Bowling, N. A. (2016). A comparison of general and workspecific personality measures as predictors of organizational citizenship behavior. International Journal of Selection and Assessment, 24(2), 172-188. https://doi.org/10.1111/ijsa.12139.

Wee, S., Newman, D. A., \& Joseph, D. L. (2014). More than g: Selection quality and adverse impact implications of considering secondstratum cognitive abilities. Journal of Applied Psychology, 99(4), 547-563. https://doi.org/10.1037/a0035183.

Werner, J. M. (2000). Implications of OCB and contextual performance for human resource management. Human Resource Management Review, 10(1), 3-24. https://doi.org/10.1016/S1053-4822(99) 00036-4.

Williams, L. J., \& Anderson, S. E. (1991). Job satisfaction and organizational commitment as predictors of organizational citizenship and in-role behaviors. Journal of Management, 17(3), 601-617. https:// doi.org/10.1177/014920639101700305.

Woehr, D. J., \& Huffcutt, A. I. (1994). Rater training for performance appraisal: A quantitative review. Journal of Occupational and Organizational Psychology, 67, 189-205. https://doi.org/10.1111/ j.2044-8325.1994.tb00562.x.

Woehr, D. J., \& Roch, S. (2012). Supervisory performance ratings. In N. Schmitt (Ed.), The Oxford handbook of personnel assessment and selection. (pp. 517-531). Oxford University Press. https://doi.org/ 10.1093/oxfordhb/9780199732579.013.0022.

Woods, S. A., \& Hampson, S. E. (2010). Predicting adult occupational environments from gender and childhood personality traits. Journal of Applied Psychology, 95(6), 1045-1057. https://doi.org/10.1037/ a0020600.

Wrzus, C., \& Mehl, M. R. (2015). Lab and/or field? Measuring personality processes and their social consequences. European Journal of Personality, 29(2), 250-271. https://doi.org/10.1002/per.1986.

Zettler, I., \& Solga, M. (2013). Not enough of a 'Dark' trait? Linking Machiavellianism to job performance. European Journal of Personality, 27(6), 545-554. https://doi.org/10.1002/per.1912.

Publisher's Note Springer Nature remains neutral with regard to jurisdictional claims in published maps and institutional affiliations. 